\title{
GENDER AND CONFLICT \\ ANALYSIS IN ISIS AFFECTED COMMUNITIES OF IRAQ
}

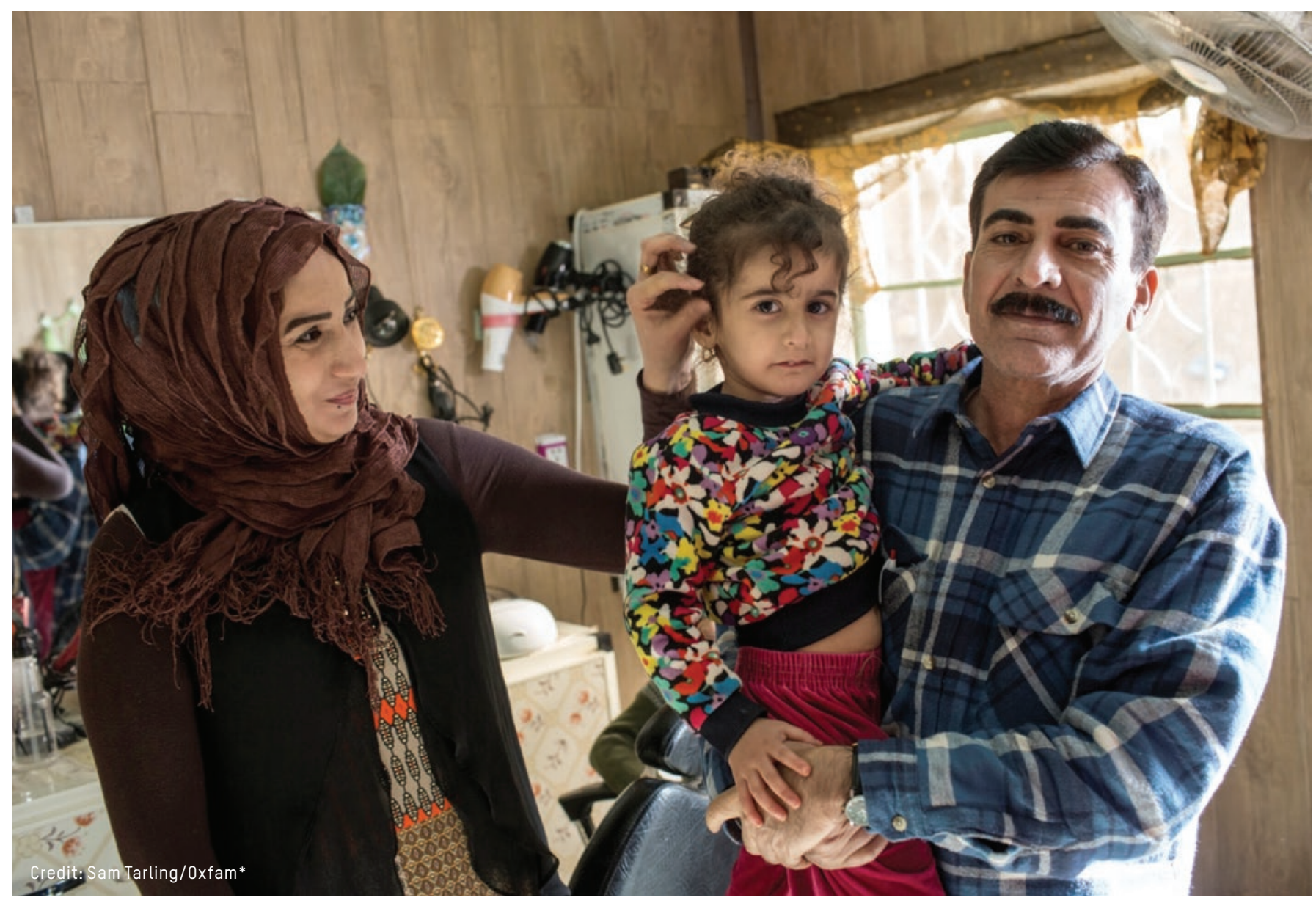

Luisa Dietrich, Gender $\&$ Conflict Analyst Simone E. Carter, Research $\delta$ Assessment Coordinator

MAY 2017

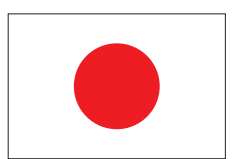

From the People of Japan

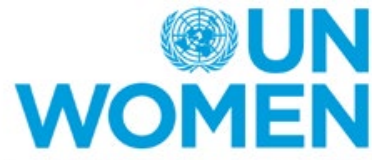

United Nations Entity for Gender Equality and the Empowerment of Women
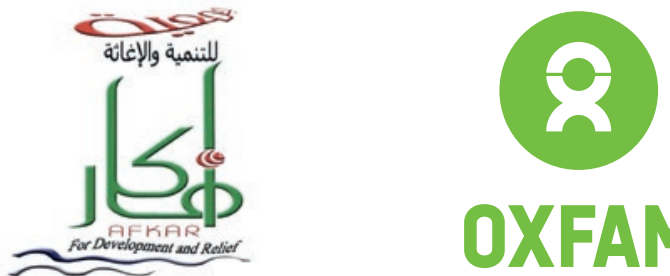

OXFAM 


\section{ACKNOWLEDGEMENTS}

It is with our greatest appreciation that we want to thank our national partner, the Afkar Society, and Oxfam's Protection staff for their engagement in this research. Thank you for your long days, your critical contributions and your feedback. We look forward to continuing working with such a great team.

With thanks also to: Akeel Adnan, Shahad Younis, Ahmed Ismael, Anmar Khalid, Marwa Farouq, Imad Ali, Mustafa Mohammed, Ahmed Mohammed, Rafal Sameer, Duaa Turkan, Elaf Zuhair, Lawn Salah, Noor Tahir, Aatef Youssef, Aram Salif and Noor Ismail.

Moreover, interviews with local experts, practitioners and activists provided additional insights for this report. We thank Hanaa Edward and Jamal Al Jawahiri (Iraqi Al Amal Association), Suzan Aref (Women Empowerment Organization), RNVDO, Suha Ouda (journalist and activist), and the Women of Mosul group.

Oxfam in Iraq would like to acknowledge the contributions of the Oxfam Gender Team, Bahar Kareem IGender Officer), Pakhshan Kakawais (Gender Coordinator Iraq), Awatef Rasheed (Project Manager,Iraq), Nesrine Jelalia (Regional Gender Adviser), Tess Dico-Young (Gender Adviser, GHT) and Justina Demetriades (Gender, Conflict $\delta$ Fragility Advisor). Additional support was provided by Haissam Minkara (Deputy Country Director, Oxfam Iraq), Saba Azeem (Business Development and Fundraising Coordinator), Anna Chernova (Conflict Sensitivity Advisor) and Yoris Kartakusumah (Data Analyst).

This research and report were made possible thanks to the support of UN Women in Iraq and the financial contribution of the Japanese Cooperation.

\section{ABOUT OXFAM IN IRAQ}

Oxfam is currently responding to the needs of Internally Displaced Persons (IDPs) and Returnees and host communities within the Disputed Internal Boundaries (DIB) and increasingly in areas affected by the recent conflict with the so-called ISIS in Iraq. As the frontline of the conflict recedes, Oxfam is expanding its operations to include new areas where IDPs are present or families have begun returning to their communities to rebuild their homes, restart livelihoods and recover from the trauma of conflict. Oxfam currently has four offices, in Erbil, Kalar, Kirkuk and Baghdad, which support programmes across the governorates of Diyala, Kirkuk, Nineveh and Salah Al Din, with plans for programming in Anbar and Baghdad in 2017.

\section{DISCLAIMER}

The views expressed in this report are those of the authors and do not necessarily reflect the views of Oxfam or any other organisation or person associated with Oxfam in the Iraq Country Office.

\footnotetext{
* Photo credit: Sam Tarling/0xfam

Emam Mahdi Saleh, 36, with her husband and youngest daughter, in her beauty salon in Jalawla, Iraq. Emam, a mother of five, was given a loan of $\$ 2000$ by $0 x f a m$ to repair her salon after it was damaged during the ISIS occupation of Jalawla. The town was controlled by ISIS between August and November 2014 . 0xfam has been helping business owners
} get back on their feet through small loans and paying people to undertake works to improve the town. 


\section{TABLE OF CONTENTS}

EXECUTIVE SUMMARY ............................................................................. 5

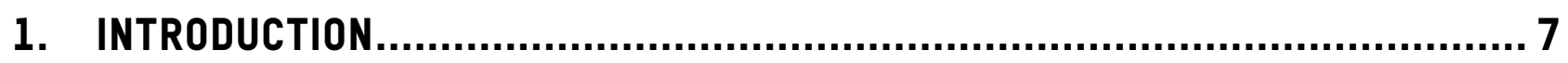

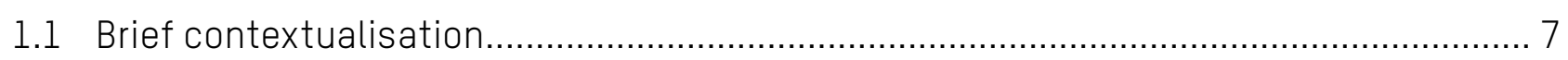

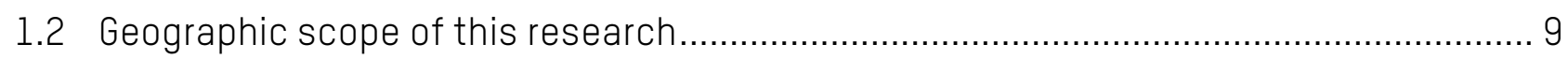

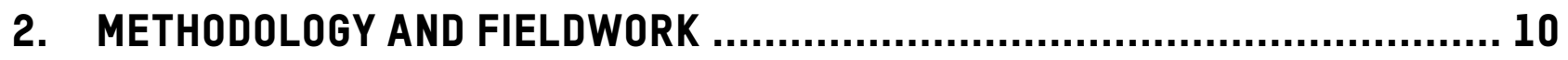

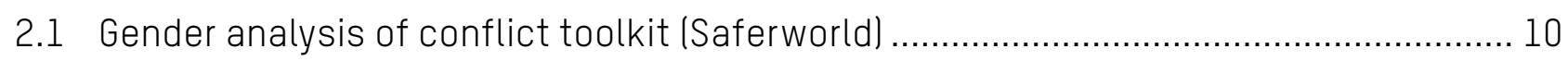

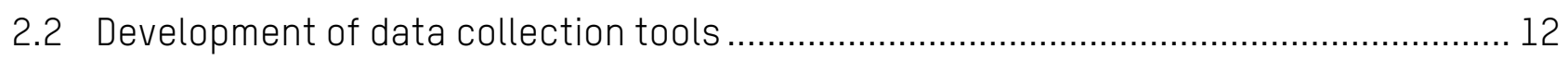

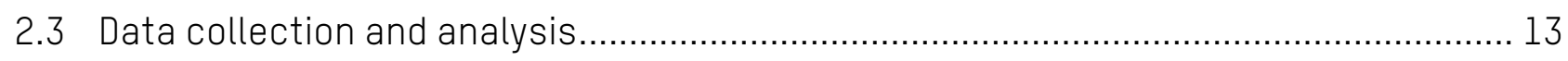

3. IMPACT OF ISIS OCCUPATION ON GENDER NORMS................................. 14

3.1 Impacts of ISIS occupation on communities and households ......................................14

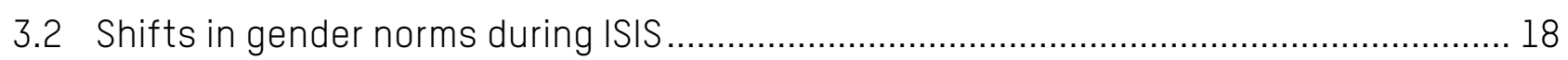

3.3 Reconfiguration of gender relations in contexts of displacement .............................. 24

4. GENDER NORMS THAT FUEL AND MITIGATE TENSIONS ............................... 27

4.1 Gender norms that fuel tensions, exacerbate insecurity and enhance vulnerability... 27

4.2 Gender norms that mitigate tensions ..................................................................... 30

\section{RECOMMENDATIONS FOR HUMANITARIAN AND RECOVERY PROGRAMMING ... 31}

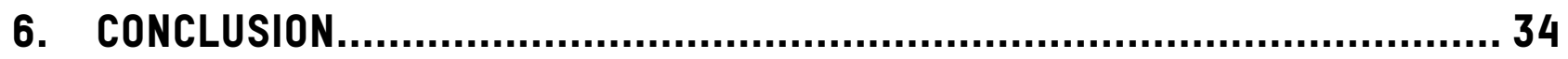

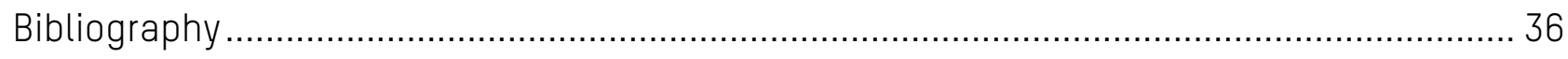

Appendix l: Women's rights and gender analysis in Iraq ................................................... 37

Apendix 2: Brief demographic information of study participants ........................................ 40 


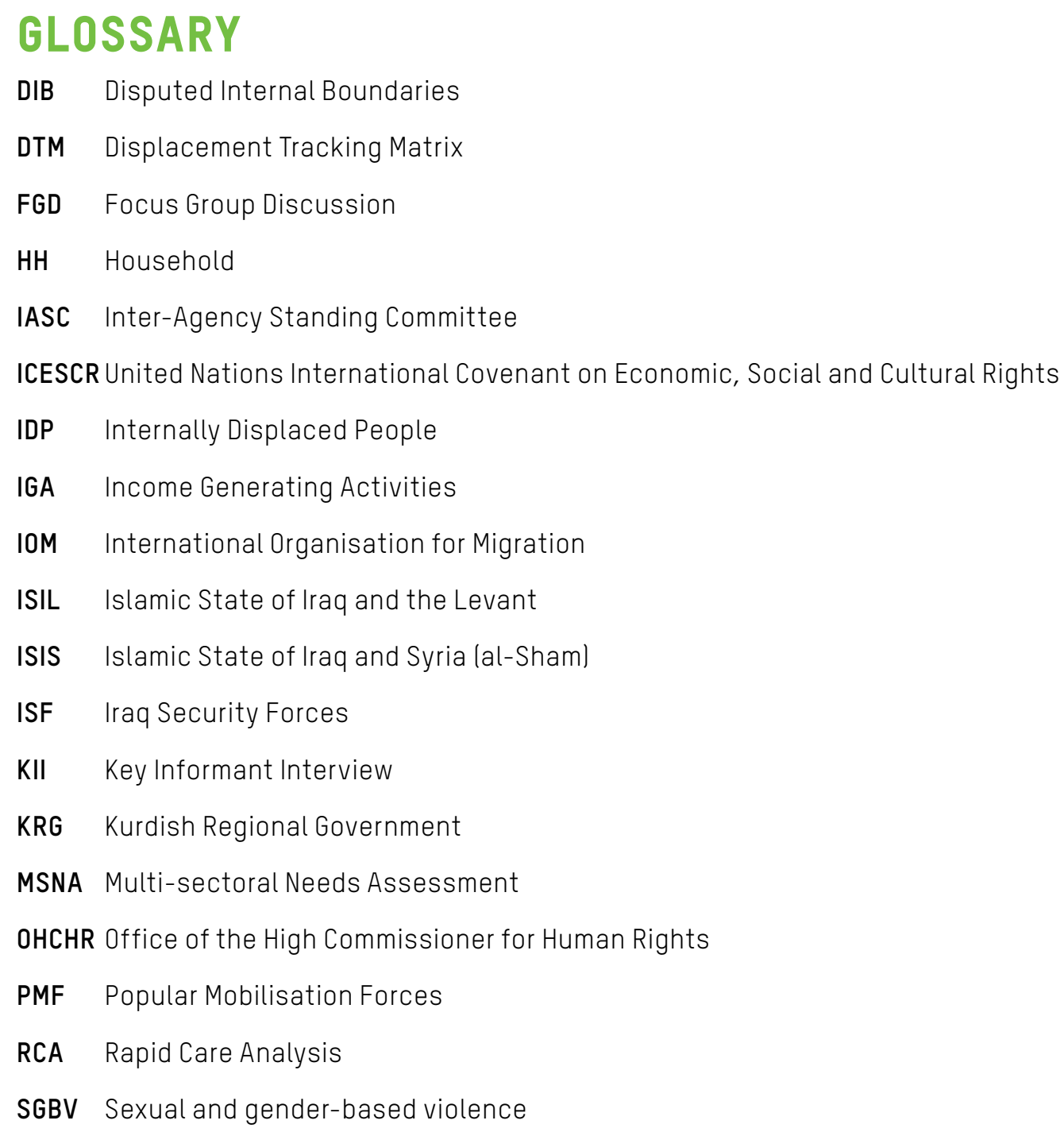

\section{LIST OF TABLES AND FIGURES}

Table 2.1: Gender analysis of conflict framework (Saferworld) ............................................................ 10

Table 2.2: Breakdown of data collection by location ............................................................................. 13

Table 3.1: Idealised qualities, traits and practices of femininity and masculinity......................................19

Table A2.1: Sex and age disaggregation of respondents, Mosul Response............................................... 40

Table A2.2: Average household composition, Anbar and Salah Al Din governorates ..................................... 40

Figure A2.1: Displacement status, Anbar and Salah Al Din governorates ................................................... 41

Figure A2.2: Marital status, Mosul dataset combined ............................................................................. 42

Figure A2.3: Percentage of respondents who reported being head of household, Mosul ............................ 42

Figure A2.4: Education and literacy level, Anbar and Salah Al Din governorates ......................................... 43

Figure A2.5: Education level of respondents, Mosul dataset ........................................................................ 43 


\section{EXECUTIVE SUMMARY}

This gender and conflict analysis of ISIS-affected communities of Iraq aims to improve understanding of gender dynamics in the context of conflict and displacement. This report sets out to identify the differential impact of ISIS occupation on women, girls, men and boys in order to explore shifts in prevailing gender norms held by study participants in Anbar, Salah Al Din and Nineveh governorates of Iraq. The objective is to enhance the understanding of the social pressures women and men experience when aiming to conform to context-specific gendered expectations of masculinity and femininity, in order to derive concrete recommendations for genderresponsive and conflict-sensitive humanitarian and recovery programming. Furthermore, this proposes concrete recommendations to adapt humanitarian and recovery programming to mitigate gendered drivers of conflict and tensions, while enhancing gendered drivers that contribute to stability and community cohesion.

\section{Methodology}

This research used the Saferworld's Gender Analysis of Conflict Toolkit, which aims to integrate gender perspectives into conflict analysis, providing a foundation for gender-responsive programming in humanitarian and recovery settings. Consequently, the toolkit intends to fill the gap between conflict analysis that lacks a strong gender lens and a gender analysis that lacks a strong conflict lens. Qualitative data following the toolkit's structure were then complemented with quantitative data asking similar questions collected concurrently with Oxfam's Multi-sectoral Needs Assessment Ithereby using one quantitative dataset to conduct two studies simultaneously and reduce the study burden on populations).

Data were collected from a 629-household survey, 24 Focus Group Discussions and 32 Key Informant Interviews across Salah Al Din, Anbar and Mosul. The sample size for the household survey provided a $95 \%$ confidence interval with a $5 \%$ margin of error. $^{1}$ Quantitative data were analysed using Marketsight software and analysis of qualitative data relied on Atlas-Ti software, which allowed the uploading and coding of the qualitative data reporting templates. Theoretical saturation was reached with qualitative data and preliminary findings triangulated during validation.

\section{Findings}

From 2014 onwards, ISIS imposed a strict social control over communities in Iraq. In response to the disruption of the social fabric, the retraction of safe public space, the conflict-induced disintegration of household units and the regulation of marriages, household members increasingly withdrew to the domestic space, which resulted in increased household tensions.

This research found that prevailing gender norms among study participants are based on a gendered difference and a gendered division of labour that tends to assign men responsibilities as protectors and providers, while designating domestic roles and responsibilities that centre on the wellbeing of their families to women. Under the ISIS occupation, study participants experienced the imposition of a set of radicalised gender norms, which included the strict separation of women from unrelated men in public spaces, aswellas rulesaboutattireand daily practices that were enforced by brutal means. Consequently, study participants tended to comply with ISIS, but have sought to revert to their prevailing beliefs and attitudes, framed around gendered division of labour and gender roles, without continuing to abide by rules imposed under ISIS occupation. The current context of displacement constitutes a space where gender roles, responsibilities and practices are being re-negotiated, thereby generating entry points for gender-responsive, as well as gender-transformative humanitarian and recovery interventions.

The exploration of gender norms that mitigate conflict and contribute to stability and community cohesion revealed that female study participants, in line with prevailing gender norms around domestic responsibilities, extended their scope of practices in the course of ISIS-occupation to interpret well-being of the family in terms of protecting their children from joining ISIS, keeping their families safe and stressing the importance of education in a context where the formal school system had been dismantled. The acknowledgement of women's diverse roles in keeping their families safe and shifts in intra-household power dynamics, constitute a possible entry point

1. Sample size calculations were conducted using Raosoft web software with a population size of $>200,000$ per governorate. See www.raosoft.com/samplesize.html 
to strengthen women's participation in contexts of displacement, as they strive to resume paid work, report an increase in joint household expenditure decision-making within the household or expressing their interest in being more involved in community decision-making.

Study participants indicate that men face considerable constraints in living up to their expected roles as the main household providers. ISIS-occupation exacerbated pressures on men who refused to join ISIS by restricting movement and forcing the closure of businesses, while the ban on women in public spaces resulted in men assuming the responsibilities of sole household providers. While access to livelihoods remains the greatest concern in displacement contexts, the humanitarian and recovery community can contribute to more flexible gender roles when promoting culturally acceptable opportunities (for women), collaborative (between husband and wife) or collective (women's cooperatives) income generation options. Furthermore, this research shows that male study participants have also extended their understanding of their roles as protectors to serve as role-models within the family in order to mitigate potential future tensions arising from and contributing to community reconstruction efforts.

\section{Recommendations}

The humanitarian and recovery community can contribute to building back better and being more accountable to the affected population. They can adapt their programme interventions to ensure not only equal and equitable access to humanitarian and recovery assistance for men and women, but also that they include shifts in gender norms that comprise beliefs, attitudes and actual behaviours in their context analysis and programme design and implementation in ways that contribute to a more egalitarian renegotiation of gender roles. Finally, gender-responsive and conflict-sensitive humanitarian and recovery programming can address the gender drivers that fuel conflict, exacerbate tensions, and increase vulnerability of the affected population, while enhancing those gender drivers that contribute to building trust, strengthening community cohesion and building resilience.

The authors propose a two-pronged approach for recommendations for humanitarian and recovery programmes:

\section{Address gendered drivers that fuel community tensions.}

- Diversify income generation opportunities to counter constructions of men as sole income providers.

- Contribute to shifts in unpaid care work by reducing the stigmatisation of men.

- Enhance targeted interventions to reach vulnerable (single/unmarried) women increasing peer-support structures.

\section{Enhance gendered drivers that build trust.}

- Generate safe spaces for women and girls to support their collective organising efforts.

- Seize opportunities to enhance women's meaningful participation at community level.

- Work with men and boys on the promotion of alternative gender roles as positive role models.

- Create and rehabilitate safe public spaces that enable the joint work of community members.

- Support local women's rights defenders and their organisations in working with survivors of SGBV.

- Contribute to an inclusive, women-led and accountable Women, Peace and Security Agenda.

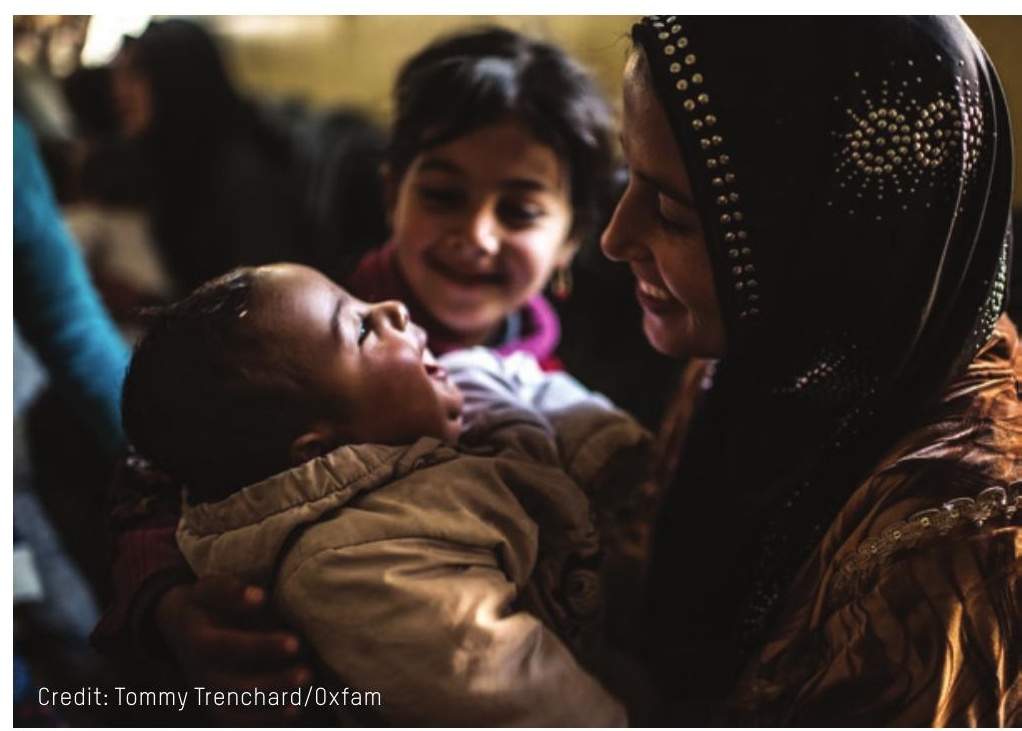




\section{INTRODUCTION}

The objective of this research is to conduct a gender and conflict analysis in ISIS ${ }^{2}$ affected communities of Iraq to improve understanding of the context and to provide recommendations for conflict-sensitive and gender-responsive humanitarian and development programming.

This research applies a research method - Gender Analysis of Conflict Toolkit ${ }^{3}$ developed by Saferworld - in three governorates in Iraq: Nineveh (Mosul), Anbar and Salah Al Din. This research aims to go beyond identifying the differential impact of conflict on women, girls, men and boys, in order to explore gendered drivers that fuel or mitigate conflict at community and household level. This study opts for an innovative approach to identify opportunities emerging from conflict-related changes in gender norms to adapt humanitarian programming in terms of what we do and how we do it. ${ }^{4}$

\subsection{BRIEF CONTEXTUALISATION}

For the past three decades, Iraq has experienced recurring cycles of armed conflict and violence, among them the Iran-Iraq war (1980-1988), the Gulf war (1990-1991) and the US-led invasion (2003-2011). Currently, Iraq is dealing with two simultaneous emergencies, classified by the InterAgency Standing Committee (IASC) at the 'L3' level, as it plays host to nearly 250,000 Syrian refugees while coping with the impact of ISIS gaining control of central parts of Iraq and occupying Mosul and Tikrit in northern Iraq. The ensuing force that repelled the attacks, as well as counter insurgency measures of the government and other regional and international forces, led to massive destruction of infrastructure and key facilities, including the homes, farms and other assets and resources of families and communities (Oxfam, 2017). The combination of food shortages, fear of airstrikes, and human rights abuses by ISIS precipitated the current displacement crisis (HRW 2016). As of 2 March 2017, the International Organisation for Migration's (IOM) Displacement Tracking Matrix (DTM) has identified 3,062,808 IDPS (i.e. 510,468 families) displaced after January 2014, dispersed across 106 districts and 3,660 locations in Iraq. For the same period, DTM has identified 1,579,362 Returnees (i.e. 263,227 families). ${ }^{5}$

\section{Emergence of ISIS in Iraq}

ISIS has its origins in 1999, originally pledging allegiance to al Qaeda; actively participating in the 2003-11 insurgency following the Western invasion of Iraq. The group pledged allegiance to Osama bin Laden in 2004. However, in 2006 when the founder (Jordanian extremist Musab al-Zarqawi) was killed, members left the group and joined with other insurgent groups to form Islamic State of Iraq (ISII). ISIS was largely born out of the US invasion of Iraq in 2003; when US administrators, decided to 'de-Baathify' the Iraqi civil and military services. Hundreds of thousands of Sunnis formerly loyal to Saddam Hussein were left without jobs and pensions, including military and intelligence officers. Al Qaeda was able to capitalise on the situation and established al Qaeda in Iraq (AQI) to stage an insurgency against US troops in Iraq ISaddam was secular, but his intelligence and military supporters were able to make common cause with the jihadis of al Qaedal using the ex-military. During this period many of their members were imprisoned in US-run 'Camp Bucca', which created another place where they were able to meet and radicalise further. By 2006, ISI controlled much of western Iraq's Anbar province. However, in 2008, a surge of US troops, with the help of Sunni tribesmen who were at odds with al Qaeda, largely defeated the group in Iraq. During the Arab Spring, AQI was able to set up a presence in Syria and renamed itself The Islamic State of Iraq and Syria (ISIS), and merged with its Syrian counterpart. This resulted in internal conflict in al Qaeda's headquarters because they were already establishing a separate al Qaeda in Syria lal-Nusra front) and wanted it to remain separate. The two groups fought amongst themselves and officially separated with $A$ QI rebranding itself into the ISIS we hear about today. As the Syrian civil war ground on, ISIS became the first rebel group to capture major cities (Raqqa and Deir ez-Zor). In the summer of 2014, the group captured Mosul and continued south until it was on the borders of Baghdad. Following this it rebranded itself as a Caliphate and demanded that all Muslims pledge allegiance (bay'ah). ${ }^{6}$

\footnotetext{
2. Sample size calculations were conducted using Raosoft web software with a population size of $>200,000$ per governorate. See www.raosoft.com/samplesize.html This report will refer to self-proclaimed Islamic State of Iraq and the Levant (ISIL), also known as Islamic State in Iraq and Syria (ISIS) interchangeably as ISIS (when reports by international organisations or academic community are cited) and Daesh (the Arabic acronym used by most study participants).

3. Gender Analysis of Conflict Toolkit, SaferWorld \& Ugand Land Alliance, June 2016. http://www.saferworld.org.uk/resources/view-resource/1076-gender-analysis-of-conflict 4. This report should be read in conjunction with Oxfam's Multi Sectoral Needs Assessment (2017).

5. IOM (2016), DTM Round 66: file:///Users/--/Downloads/Round66_Report_English_2017_March_02_I0M_DTM.pdf 


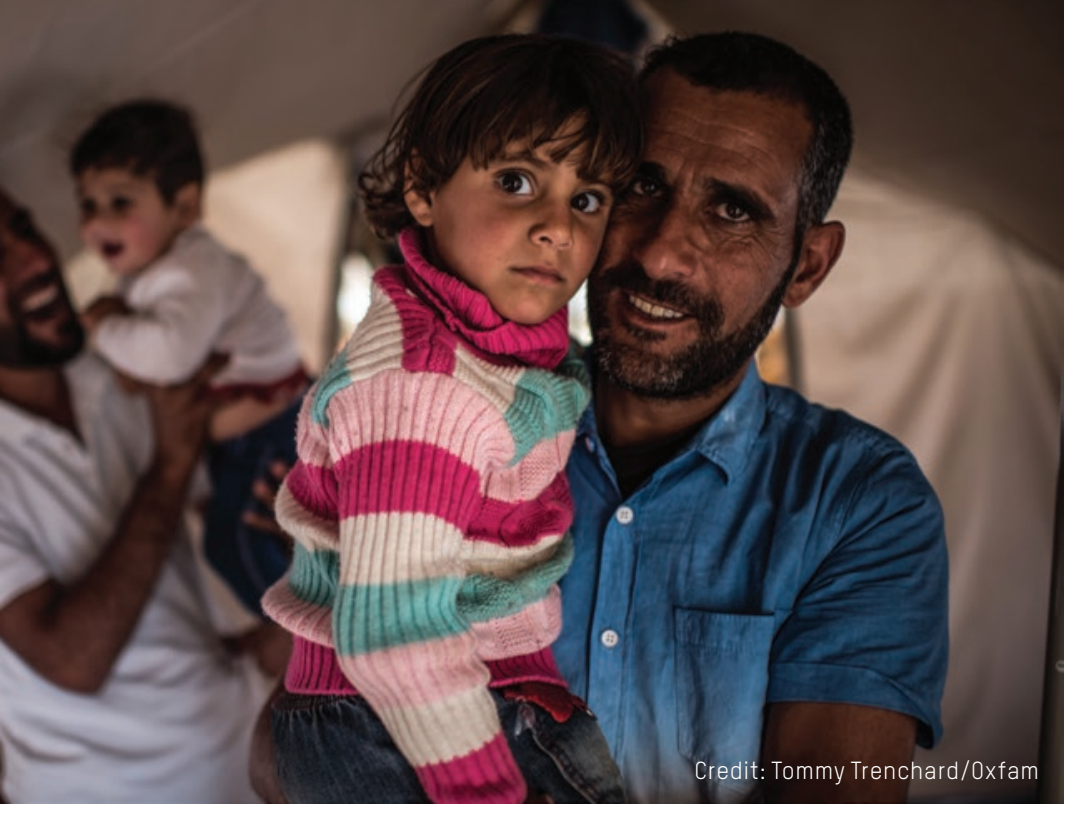

Since the establishment of ISIS in 2014, the organisation was able to mobilise support by linking Iraqi Security Forces (ISF) and political forces with the armed opposition groups (Shia militia) who have perpetrated abuses against the local population for several years and exploit strong concerns over Iran's involvement in the area (Dagher, 2014). According to Dagher (2014), the US involvement was presented as a 'new crusade of Christians against Muslims', while claiming themselves as defenders of Sunni values. However, their actions are contrary to the Sunni practices and traditions of the area (Dagher, 2014). Consequently, study participants report that in Mosul, 'we didn't hear any fire, we woke up in the morning and the city was already under ISIS control. The city was taken by car honks, not bullet fire. In the early phases IS control was in part positive, or at least better than the Iraq army, but that opinion did not last for long' (Hassan Sham, KII, Male). Furthermore, a woman from Jeddah camp reports: 'in the beginning we felt safe and comfortable because ISIS rescued us from arrests by the Iraq army' (Jeddah camp, KII, Female). Consequently, recruitment mechanisms fuelled resentment against ISF. As a study participant recalls: 'I know a person who was arrested several times by the Iraqi army. So when Daesh came, he joined Daesh' (Hassan Sham, KII, Man).

\section{Perception of conflict causes and actors}

This research focuses on ISIS-affected communities in Nineveh, Salah Al Din and Anbar. Study participants report that the conflict is not yet over, as ISIS still controls entire sections of villages and city neighbourhoods. Among the multiple armed actors are ISIS and various affiliated armed opposition groups and (Sunni) tribes, some of whom support ISIS and some of whom oppose them; the Iraqi Security Forces (ISF) and aligned Popular Mobilisation Forces (PMF); the Kurdish peshmerga and the Kurdish Regional Government's (KRG) armed forces, and different regional actors, including Syria, Iran, Turkey, and the Gulf States (Rohwerder, 2014).

The multi-faceted and complex perceptions around conflict causes put forth by Rohwerder (2014) and confirmed by study participants include:

1. Alienation as a result of the 'sectarianisation' of the political system, which has left many Sunnis lacking trust in state institutions and a weakening sense of Iraqi identity. Furthermore, perceived corruption and exclusionary policies and injustice, as well as competing interest among political parties, are cited as root causes. At the same time, $31 \%$ of respondents from areas of Oxfam's Mosul response consider the state to be responsible for the current armed conflict, while another $25 \%$ consider politicians to be primarily responsible.

2. Feelings of insecurity as a result of the increasing Shia make-up of Iraqi Security Forces and unregulated and unaccountable sectarian militias. Sectarian attacks have helped to perpetuate the conflict. 'We are afraid of the Popular Mobilisation Forces (PMF) because they are Shia and in our place we are mostly Sunni' (Hassan Sham camp, KII, Female).

3. Underlying structural tensions including lack of services, education and employment and discrimination against minorities. Consequently, other potential for tensions emerges along ethnic lines between Kurds and Arabs and/or between IDPs, host communities, Returnees and Remainees.

7. According to Rohwerder (2014), these include Sunni armed groups ranging from secular nationalist to Salafist jihadist, who work together and occasionally in opposition to each other 


\section{Women's multiple roles under ISIS occupation}

ISIS is composed predominantly of male members and is based on a male decision-making structure. However, 'when State-building became a goal, ISIS began to actively encourage Muslim women to join them in their newly founded "Caliphate"' as an "Islamic state would be impossible without wives and mothers who, alongside their male fighters, would breed future generations and accomplish domestic duties upon which ISIS's vision of society depends' (Jacoby, 2015:535).

In the context of ISIS occupation, women have played multiple roles and resorted to different coping strategies. For example, women have kept families united, protected their children from being forcefully recruited, have contributed in their roles as educators and in de-radicalisation. In particular, female-headed households have overcome barriers to provide for their children. Local women's organisations run women's shelters to address the needs of women and girls who have escaped attempts of 'honour killings'. Women's Rights and Women Human's Rights defenders have been assassinated, faced threats, kidnappings, insults and intimidation against themselves and their families in an attempt to silence them. Despite all these restrictions, many women have been organising informally, trying to make their voices heard, documenting and publishing abuses of women's human rights and trying to find a space for themselves in a highly hostile environment. Women have engaged in armed confrontations against ISIS, particularly Kurdish female fighters. Women

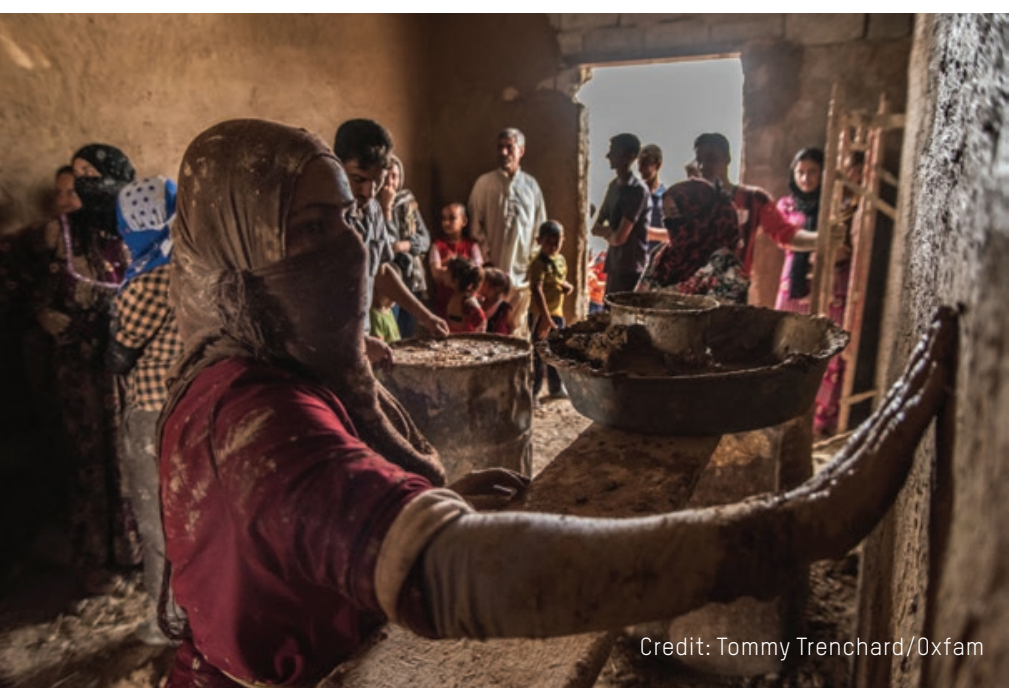

and girls have been abducted, survived sexual and gender based violence (AI, 2014), escaped, spoken publically about the human rights abuses suffered and are leading the struggle to hold ISIS perpetrators accountable. Women have also served as nurses, doctors and teachers within ISIS's attempt at statebuilding, have worked as recruiters, propagandists and inciters, and served in ISIS's morality police force, enforcing rules upon other women (HRW, 2016; Eggert, 2015). Consequently, in the current context of the humanitarian crisis in Iraq, women do not necessarily conform to perceptions characterising women as victims of extremism, and have valuable experience, ideas and contributions to inclusive peace-building and reconstruction processes.

\subsection{Geographic scope of this research}

The selection of study locations reflects considerations about the focus on areas that are most affected by the ISIS conflict in Iraq, and in which Oxfam has ongoing or foreseen interventions. This decision was motivated by the pragmatic choice of having a pre-secured access to the communities and areas that will be part of this research, but also by ethical research principles that recommend the set-up of programming to address the needs and interests of the community following the research.

For the Mosul response, study locations include Jeddah camp and host-community, as well as Hassan Sham camp. In Salah Al Din governorate, fieldwork was conducted in twelve communities (villages and neighbourhoods) in Tikrit, Samarra and Baiji. In Anbar governorate, the study covered 13 communities in four districts, Heet, Fallujah, Ramadi and Khaldiya. The selection criteria identifying the most affected areas included the destruction of infrastructure, the number of IDPs and the number of Returnees. Furthermore, a combination of urban and rural locations was selected in accordance with different housing arrangements (shelters, houses, abandoned buildings and camp settingl and used IOM's Displacement Tracking Matrix to jointly agree with Oxfam's partner, the Afkar Society, on study locations. Where possible, the findings of this research are contrasted with completed gender research efforts and lessons learned from gender responsive programming in Diyala and Kirkuk governorates. 


\section{METHODOLOGY AND FIELDWORK}

\subsection{GENDER ANALYSIS OF CONFLICT TOOLKIT (SAFERWORLD) ${ }^{8}$}

Among the objectives of Saferworld's toolkit is integrating gender perspectives into conflict analysis, providing a foundation for genderresponsive programming in humanitarian and development settings. Consequently, the toolkit intends to fill the gap between conflict analysis that lacks a strong gender lens and a gender analysis that lacks a strong conflict lens.

\section{For the humanitarian community this approach contributes in two ways:}

1. Identifying how women, girls, men and boys have been affected differently by armed conflict, insecurity and community tensions laccording to ethnic, religious and economic background) in order to better understand who to work with to change attitudes and address particular vulnerabilities.

2. Adding how gender norms (i.e. the ways in which societies pressure their male and female members to behave) relate to conflict on national, regional, community and household levels. A better understanding of the social pressures men and women experience in order to live up to context

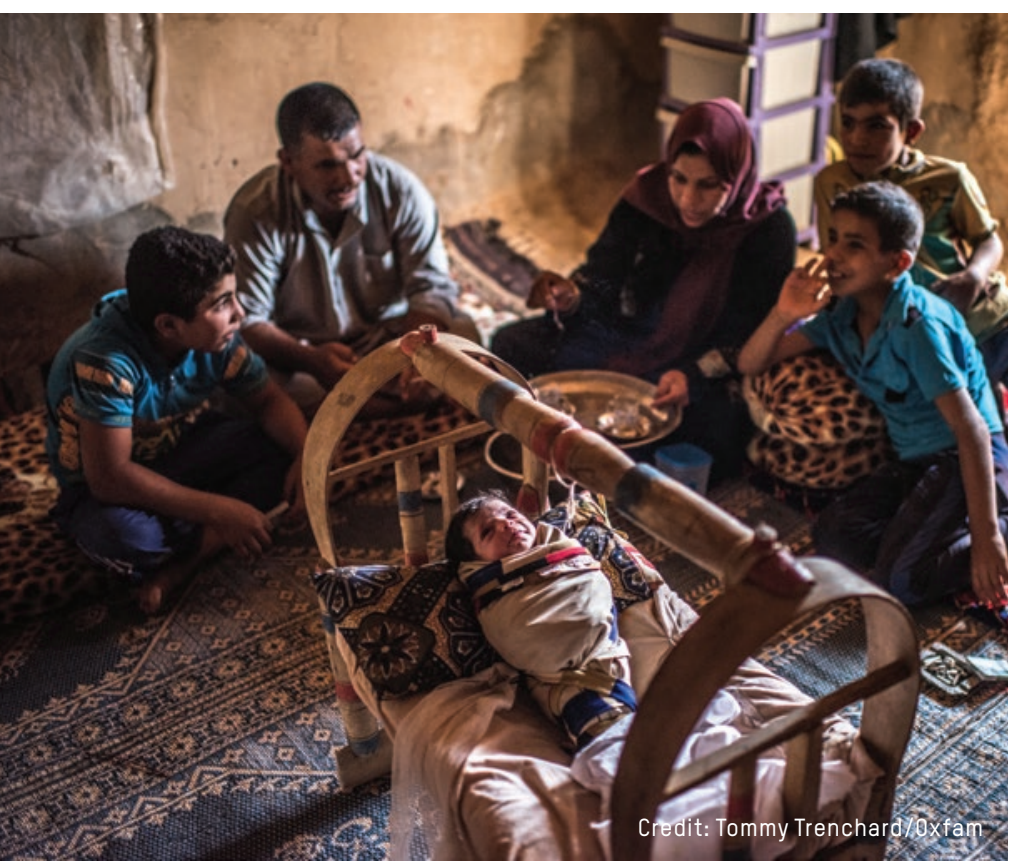

specific gendered expectations of masculinity and femininity has the potential to identify those gender norms that either drive conflict and insecurity or contribute to building trust and social cohesion. Consequently, these concrete entry points inform design of conflict-sensitive and gender-responsive humanitarian interventions that feed into gender justice, active citizenship and a rights-based economic justice programming.

\section{As the toolkit stresses:}

'Gender norms are not just about the attitudes and beliefs held by individuals, but are produced and perpetuated by political, economic, cultural and social structures, including education systems, the media, religious institutions, welfare systems, and security and justice systems. It is important to distinguish between norms and people's actual behaviours: whereas norms describe social pressures to behave in a certain way, people's behaviours (how they act or conduct themselves) do not always conform to those norms. The costs of not conforming to gender norms vary, but can be high, including shaming and social exclusion, violence and even death. (Saferworld, 2016:2).

Furthermore, the strategic contribution of this toolkit to standard conflict analysis is explained as follows: While a standard conflict profile outlines the broad social, economic, demographic, political and historical context of the conflict, a gender analysis of conflict approach adds an understanding of what gender norms exist in a localised conflictaffected context and how they compare to people's actual behaviours. Furthermore, while a standard actor analysis maps out the key actors involved in fuelling the conflict or in a position to promote peace, a gender analysis of conflict approach adds an understanding of the roles women and men play in conflict and peace-building. Finally, while a standard exploration of peace-building opportunities identifies existing initiatives and potential future strategies to work towards peaceful change, a gender analysis of conflict approach adds ideas about which gender norms or behaviours could be challenged or enhanced to promote peace.

The gender analysis of conflict framework is divided into two parts - 1) understanding gender norms and behaviours and 2) gender analysis of conflict. It is organised around ten questions. 


\section{Table 2.1: Gender Analysis of Conflict Framework (Saferworld)}

\begin{tabular}{|l|l|}
\hline $\begin{array}{l}\text { Understanding } \\
\text { gender norms } \\
\text { and behaviours }\end{array}$ & $\begin{array}{l}\text { 1. What roles do people of different genders play in the community? } \\
\text { 2. What are the predominant gender norms for different social groups? }\end{array}$ \\
\hline $\begin{array}{l}\text { Gender analysis } \\
\text { of conflict }\end{array}$ & $\begin{array}{l}\text { 7. How have norms relating to masculinity and femininity been shaped and changed by conflict? } \\
\text { f. Wow are men, women and sexual and gender minorities (SGM }{ }^{9} \text { ) and their gender roles affected } \\
\text { conflict? }\end{array}$ \\
$\begin{array}{l}\text { 8. How do gender norms and behaviours shape how violence is used, by whom and against whom? } \\
\text { 9. Do norms relating to masculinity and femininity fuel conflict and insecurity in this context? } \\
\text { 10. Are there norms relating to masculinity and femininity, which (could) help build or facilitate } \\
\text { peace? }\end{array}$
\end{tabular}

In order to answer these questions, the toolkit proposes a series of workshop-style exercises ${ }^{10}$ to be completed in a participatory manner with conflict-affected communities.

\section{Adapting and contextualising the tool}

Among the challenges of the practical application of this toolkit is the adaptation to localised contexts, in this case communities that have lived under ISISoccupation for up to two years and are currently living in contexts of displacement as IDPs, Returnees or Remainees and the host-community. As humanitarian actors, expanding operations into areas where ISIS has receded and lost territorial control shaped the adaptation of the toolkit. The planning phase for the gender and conflict analysis coincided with Oxfam's Multi Sectoral Needs Assessment (MSNA) envisaged for Salah Al Din and Anbar governorates and consequently allowed for integrated fieldwork. The motivation to collect representative quantitative data aiming to cover 25 villages and neighbourhoods and work with local partner enumerators instead of a trained facilitator team, led to the decision to conduct more-standardised data collection, including quantitative household surveys, Focus Group Discussions (FGDs) and Key Informant Interviews (KIIS), instead of workshop-style exercises. While this decision was appropriate to the prevailing security context ${ }^{11}$ - distrust in the communities, actors, and movement restrictions constraining time of permanence in each locations - participatory and community ownership over the research process, stressed in Saferworld's toolkit, was limited.

Finally, it needs to be noted that this toolkit does not set out to document the prevalence or patterns of SGBV. We acknowledge that specialised organisations are better equipped to gather sensitive information in a dignified manner for SGBV survivors, linking documentation to required psycho-social, health-related and judicial assistance. In line with the Interagency Standing Committee (IASC) GBV Guidelines, which state: 'all humanitarian personnel ought to assume GBV is occurring and threatening affected populations; treat it as a serious and life-threatening problem; and take actions based on sector recommendations in these Guidelines, regardless of the presence or absence of concrete "evidence"' (IASC, 2016:2), this research does not gather evidence. However, where references to SGBV emerged as an effect of conflict, occurrence was included in this report.

9. 'Sexual and gender minorities' (SGMs) is an umbrella term which refers to people whose sexual orientation or gender identity does not fit within conventional societal norms. Internationally, lesbian, gay, bisexual, queer, transgender, transsexual and intersex identities are gaining increasing recognition.

10. Exercise 1: Daily routines; Exercise 2: Access to and control of assets; Exercise 3: Understanding masculinity and femininity; Exercise 4: Gender norms vs behaviours; Exercise 5: How conflict shapes gender; Exercise 6: Peace and conflict: gender roles and impacts; Exercise 7: How conflicts are resolved; Exercise 8: Gender norms - drivers of conflict or peace?; Exercise 9: Gendered institutions and structures.

11. While in Hassan Sham and Jeddah Camp, Oxfam has ongoing programmes and access, Anbar and Salah Al Din continue to experience tensions, including communities that remain blocked off (either by police or still remaining under Daesh control), where checkpoints and security can change regularly. Afkar staff obtained permits to move within the districts. However, despite these, some areas remained inaccessible. 


\subsection{DEVELOPMENT OF DATA COLLECTION TOOLS}

\section{Pilot test for the Mosul Response}

The development of qualitative and quantitative data collection tools drew on a revision of the pilot testing (December 2016 to February 2017) in two locations of Oxfam's Mosul response, Jeddah camp and host-community and Hassan Sham camp. Pilot testing was completed by a team of four enumerators (two females and two males) under the guidance of Oxfam's Gender Team, composed of the national gender officer, the national gender coordinator and the regional gender adviser.

Quantitative data collection used a household survey that comprised 60 questions in the following six thematic areas: demographic information; livelihoods and gendered division of labour; decision-making and voice; gender norms; conflict affectation; and return and future life. Household surveys were completed using handheld devices operating on the Mobenzi quantitative data collection platform. Out of the total of 239 household surveys applied, 65 surveys (39 women and 26 men) were completed in Jeddah camp and 174 surveys (105 women and 69 men) in Hassan Sham camp.

Qualitative data collection used a semi-structured questionnaire for FGDs that included workshoplike activities in accordance with Saferworld's Gender Analysis of Conflict Toolkit. In total, eight FGDs (five women-only and three men-only) were completed. Five complementary expert interviews were conducted with women's rights activists, researchers and practitioners. Qualitative data gathered in the course of FGDs and expert interviews were summarised, and served not only to triangulate quantitative data, but also to feed into the adaptation of research tools and the analysis of this report.

\section{Planning Phase \\ Development of tools}

Quantitative data collection tools included the MSNA household survey, drafted by the Research Coordinator and then reviewed with technical teams. The final MSNA household survey comprised a set of 100 questions, with sections on household information; displacement information; gender and conflict analysis; coping mechanisms, livelihood and markets; water, sanitation and hygiene/public health; self and community based protection; communication with affected populations, and perceptions of the humanitarian assistance.

Qualitative data collection for the gender analysis of conflict component comprised the development of separate sets of guided questionnaire for FGDs, shorter and discussion oriented; and Klls, more extended, also addressing more sensitive questions (for example around intimate partner violence) with community members, which also served as a reporting template for enumerators. Guided questions for FGDs and KIls with community members focused on following overarching themes: community tensions and groups/people responsible; violence experienced by women and men (of different ages); changes in gender norms due to the conflict; and roles in reducing and/or contributing to community tensions. Qualitative tools were adapted for maleonly and women-only groups and each group was asked about their perceptions on, and implications for, women and men, while also allowing for flexibility to address the same issue from different angles. For example, when exploring women's disposition to engage in paid work outside the home and preferred livelihood option, questions for men were framed around the disposition to 'allow' women's work outside the home. All survey tools were developed in English, translated into Arabic using professional translation services, and then reviewed by Oxfam Arabic speaking staff to ensure correct meaning, and double-checked by partner enumerators familiar to the context, with regard to the appropriateness of questions.

\section{Composition of teams and training for enumerators}

The Mosul enumerator team that conducted the pilot also applied revised qualitative and quantitative data in Jeddah camp and Hassan Sham. The team consisted of two women and two men, who worked as part of Oxfam's gender team. The Anbar and Salah Al Din teams comprised two female and three male enumerators each, amounting to six male and four female enumerators, who had been working with Oxfam's partner organisation, the Afkar Society, previous to this study. All 14 enumerators participated in a three-day training in Erbil at the beginning of the study on how to conduct FGDs and interviews, how 
to manage any incidents during data collection and how to be transparent with communities in the course of fieldwork. During the weeks of data collection, twice-weekly Skype calls were organised with partner staff to answer concrete questions and to provide feedback on data collection. However, challenges included limited internet connectivity, language barriers and a study timeframe that did not permit the use of pilot tools in the partner areas.

\subsection{DATA COLLECTION AND ANALYSIS}

\section{Fieldwork}

Fieldwork in the study locations was completed between 12 February and 8 March 2017. In total 629 household surveys were completed in two separate datasets: the Mosul response pilot dataset with 239 household surveys (144 female and 95 male); and the MSNA dataset in Salah Al Din and Anbar governorates comprising a total of 390 randomly selected households (representing 2,340 individuals). In terms of qualitative data collection there were $24 \mathrm{FGDs}, 27 \mathrm{KIl}$ s with community members and five KIIs with experts (Mosul pilot). Salah Al Din, fieldwork was conducted in three districts, Tikrit, Samarra and Baiji. In total, 175 household surveys (68 female and 107 male respondents), six FGDs (5 woman-only and 1 male-only) and six KIls ( 4 women and 2 men) were completed. In Anbar, fieldwork was conducted in four districts, Fallujah, Ramadi, Heet, Khalidya. In total, 215 household surveys ( 82 female and 133 male respondents) were completed and complemented with six FGDs $(3$ male-only and 3 female-only) and four KIIs ( 3 female and 1 male). In locations of Oxfam's Mosul Response no additional household surveys were completed, while additional rounds of qualitative data collection included four FGDs ( 2 female-only and 2 male-only) and a total of $17 \mathrm{KIIs}$ ( 9 male and 8 female).

\section{Table 2.2: Breakdown of data collection by location}

\section{e 2.2: Breakdown of data collection by location}

\begin{tabular}{|c|c|c|c|c|c|c|c|}
\hline Governorate & $\begin{array}{l}\text { District } \\
\text { (Village) }\end{array}$ & $\begin{array}{l}\text { HH } \\
\text { Survey }\end{array}$ & $\begin{array}{l}\text { FGD } \\
\text { (Male) }\end{array}$ & $\begin{array}{l}\text { FGD } \\
\text { (Female) }\end{array}$ & $\begin{array}{l}\text { KII } \\
\text { (Male) }\end{array}$ & $\begin{array}{l}\text { KII } \\
\text { (Female) }\end{array}$ & $\begin{array}{l}\text { KII } \\
\text { (experts) }\end{array}$ \\
\hline \multirow{3}{*}{ Salah Al Din } & Tikrit & 82 & 1 & 2 & & 3 & \\
\hline & Samarra & 45 & & 1 & 1 & & \\
\hline & Baiji & 48 & & 2 & 1 & 1 & \\
\hline \multirow{4}{*}{ Anbar } & Fallujah & 69 & 1 & & & 1 & \\
\hline & Ramadi & 53 & 1 & & & & \\
\hline & Heet & 69 & & 2 & 1 & 2 & \\
\hline & Khalidya & 24 & 1 & 1 & & & \\
\hline \multirow{2}{*}{$\begin{array}{l}\text { Mosul (Nineveh/ } \\
\text { Erbil) }\end{array}$} & (Jeddah camp) & 65 & 1 & 2 & 5 & 4 & 5 \\
\hline & Hassan Sham (camp) & 174 & 4 & 5 & 4 & 4 & \\
\hline TOTAL & & 629 & 9 & 15 & 12 & 15 & 5 \\
\hline
\end{tabular}

\section{Data analysis}

Quantitative data collected using handheld devices were downloaded from Mobenzi research console and cleaned using Excel. Data analysis was facilitated by online data analysis software (Marketsight) for the Anbar and Salah Al Din quantitative dataset. The software allows data to be uploaded and cross- tabulated using a 95\% confidence interval and $5 \%$ margin of error for both governorates together, ${ }^{12}$ while running a regression analysis via the software and highlighting statistically significant data. Analysis of qualitative data relied on Atlas-Ti software, which allowed the uploading and coding of the qualitative

12. Sample size calculations were conducted using Raosoft web software with a population size of > 200,000 per governorate. See www.raosoft.com/samplesize.html 
data reporting templates. A total of 65 initial codes were originally developed, then combined into 30 thematic codes across nine code categories. Theoretical saturation was reached with qualitative data and preliminary findings triangulated during validation.

\section{Validation}

The data collection fieldwork ended with a validation session; a two day workshop with all team members who participated in data collection. Additionally, two Oxfam protection team members were present to support and facilitate sessions. A total of 19 oxfam and Afkar Society staff worked together over two days to review, confirm and validate data, to clarify information, and to fill in gaps where some data was either missing or contradictory. During the validation workshop, the enumerator teams also provided additional observations contributing to the depth of data and analysis. The validation workshop included sessions on vulnerability, perceptions of conflict tensions and changes in power dynamics within the household.

\section{IMPACT OF ISIS OCCUPATION ON GENDER NORMS}

This section explores the differential impact of ISIS occupation on women, girls, men and boys and explores crisis-induced shifts in prevailing gender norms among female and male study participants from Nineveh, Anbar and Salah Al-Din governorates.

\subsection{IMPACTS OF ISIS OCCUPATION ON COMMUNITIES AND HOUSEHOLDS}

This section explores the impact of ISIS occupation on communities and households in order to provide a general context on how prevailing gender norms were radicalised during ISIS occupation and shaped the conditions of displacement.

\section{Disruption of value system and social fabric}

A key rationale of ISIS's control over the territory aimed at destroying the social fabric and community cohesion. ${ }^{13}$ Female and male study participants reported constant fear of and random harassment by ISIS members and increasing distrust among community members. As noted by an NGO representative interviewed, most members and sympathisers of ISIS did not suddenly arrive, but were local people: 'People realised that their neighbours, members of their families, their friends turned out to be part of dormant cells of ISIS. So the fear of the "other" became very prominent.' ${ }^{14}$ ISIS also installed a network of informants, paying them small amounts of money to denounce people. These informants readily complied due to their precarious financial situation. ${ }^{15}$ Consequently, study participants spoke of the distrust among neighbours, who readily denounced (perceived) transgression of rules to ISIS authorities, which led to the disruption of the social fabric at community level.

The disrupion of the social fabric also emerged as a result of ISIS targeting declared enemy forces. ISIS not only pursued members of executive forces of the Central and Kurdish governments as military targets, but also threatened the immediate and extended families of army and police personnel. Consequently, study participants reported efforts, where possible, to keep such associations concealed and reduced their social contacts in order to avoid being attacked, abducted or otherwise harassed. The fear of being targeted for kinship-association to soldiers or police forces becomes evident in the following quote: 'my son in law works with the Peshmerga forces and if ISIS had known that I was in contact with him they would kill me and my family' (Hassan Sham, KII, Woman). Another study participant recalls an acquaintance: 'This woman was much more vulnerable than other community members, because two of her sons were soldiers and her husband had retired from the Iraqi military. ISIS used to raid their house late at night to check on them, which stressed the mother very much (Jeddah, KII, Male). Often community members turned on each other to denounce and reveal these types of kinship associations to ISIS militants. This results in increasingly weak social cohesion in communities under ISIS control.

The fragmentation of the social fabric also extends to shifts in decision-making power at community level, as ISIS set out to co-opt or replace traditional decision-making spaces and authorities: 'Daesh decreased the role and consequently the respect of the Sheik or Mokthar, now they are weak and lack capacity as community leaders' IJeddah Host community, KII, Man). Study participants explain that Imams and other faith-based authorities were

13. The UN Women Global Study on the implementation of United Nations Security Council Resolution 1325, Preventing Conflict, Transforming Justice, Securing the Peace (2015) puts forth that groups like ISIS ground their violence on an ability to govern and control territory (UN Women 2015) and proceed with extreme brutality enforcing their rule.

14. Transcript of interview with Suzan Aref, Coordinator of National Task force for Iraq's Res 1325 NAP, Director general of Women Empowerment Organization, December 24 th, 2016. 15. Expert interview. 
blamed for their perceived empathy and cooperation with Daesh. Quantitative data captured in the MSNA household surveys also indicate that authority for protecting communities and resolving disputes shifted from Mokthars to the Iraq army and police. Undermining the trust in former authority figures also reduced the possibility of organised or collective resistance.

ISIS also pursued proactive recruitment strategies mobilising rural male youth from villages outside Mosul, where employment, literacy and income rates were much lower (Dagher, 2014). Furthermore, ISIS used deprivation of access to services and livelihood opportunities in order to push community members into joining their group: 'You need to provide the basic things for your family, and this was one way Daesh encouraged people to join them' (Hassan Sham, KII, Female). However, opportunism is also cited as means to recruit new members: 'Most of the rich people in the community joined ISIS because they don't want their trade to be affected by the situation Daesh imposed' (Jeddah camp, FGD, Women). Furthermore, coerced and forced marriage between ISIS fighters and loften under-aged) girls and women was yet another way to bind the woman's family network to the organisation. These different strategies of recruitment further fragmented the community, introducing yet another distinction between those families with allegiance to ISIS and those, who despite all the hardship refused to join, resulting in complex power relations within communities that persist in the context of displacement.

\section{Scaling-back of public space}

The tight social control imposed by ISIS resulted in a notable scaling-back or retraction of the public space. Forced movement restrictions, harassment at roadblocks, abductions, and arbitrary imprisonment instilled fear among community members as well as a widespread lack of safety. In addition, ISIS largely imposed a ban on women moving in public spaces without a male relative, while enforcing strict rules of attire. Recurrent references were made to women's harassment on the street, particularly 'men in big cars harassing female adolescents' (Jeddah camp, KII, Woman). Children would stop going to school because of to security concerns and a 'lack of qualified teachers, some of whom fled ahead of the ISIS attack, or because ISIS had changed the curriculum to study of the Quran, fighting techniques, and instructions on how to make improvised explosive devices' (HRW, 2016). Consequently, household members reduced time spent outside their homes, limiting leisure activities, such as casual gatherings at street-corners (among men) or family visits to parks. The retraction of safe public space not only impacted negatively on the prospect of pursuing livelihood opportunities, but also increased tensions within the household. Consequently, the lack of safe public spaces, such as parks or public sporting facilities emerged as recurrent need in the narratives of study participants and more than this, 'leisure activities' should be seen by humanitarian actors as means to re-establish community relations and to reduce potential tensions underlying the situation of displacement.

\section{Conflict related disintegration of household units}

Because of the retraction of the public space and a ban on women's free movement, men constituted the majority of casualties who disappeared or were imprisoned by ISIS. Some female study participants consider men particularly vulnerable, 'because of the available security situation and the lack of security for men in general' (Salah Al Din, KII, Woman). The qualitative and quantitative research tools explored the disintegration of household units in terms of killing of family members lincluding heads of household), abduction, recruitment under the age of 18, trafficking, separation of household members and assassination of children. ${ }^{16}$ Reported reasons for household disintegration relate less to armed combat, and more to brutal enforcement of social control and efforts to intimidate community members. Examples thereof relate to the death of household members as a result of ISIS imposed roadblocks restricting access in cases of medical emergencies (Jeddah camp, KII, Female). In addition, study participants referred to households affected in multiple ways, as a female study participant from Hassan Sham camp reports: 'There is a family my husband knows. Two of their children joined Daesh because they didn't have money to live. The oldest son was killed, the second son exploded himself and the wife left them because when they joined ISIS, she objected to that from the beginning.' IHassan Sham camp, KII, Female). In addition to the human

16. For more information refer to Oxfam's Multi-Sectoral Needs Assessment in Anbar and Salah Al Din, published in May 2017. 
rights violations experience under ISIS occupation, displaced people face uncertainty about the fate of family members of those who where abducted, imprisoned or were separated in the course of displacement. In addition, the effects of household disintegration puts households without or with few members of income-generating age at risk of resorting to high-risk coping strategies. Femaleheaded households without adolescents and youth were perceived as particularly vulnerable because of conflict-related household disintegration.

\section{Regulation of marriages}

The control exerted by ISIS relates not only to communities, but also extends to regulating the relations between husbands and wives. While the imposition and enforcement of gendered behavioural rules by ISIS will be explored further below, this section aims to show the widespread reach of ISIS in controlling people living under their jurisdiction. As a male study participants reported: 'ISIS in three years controlled everything and destroyed the relationship between husbands and wives' (Jeddah camp, KII, Man). Furthermore,

ISIS decided everything and left no room for personal decisions. ISIS decided for our wives what to wear and what not to wear, they did not let women decide on their own, or let the husband decide what he likes his wife to wear. They were deciding what to do, how to live, how to work, where to stay or go (Anbar, Ramadi, KII, Man).

ISIS enforced compliance to their norms by punishing men for perceived transgressions of their wives, sisters and daughters: "if she failed to comply to ISIS's rules, her husband would be punished instead of her' (Jeddah camp, KII, Man). Punishment ranged from fines and confiscation of identity documents to public humiliation of men in front of their family and community, as reported in instances of public lashing if wives (or female relatives) were found to have failed to comply with rules of attire or about not going to the market without a male relative. Consequently, female study participants were forced to comply with imposed dress codes to avoid the punishment of their male relatives. Failure to do so arguably increased tensions within the home. While some male respondents perceived public humiliation and being coerced by ISIS into asserting their authority against their female relatives as disempowering, others reported embracing the additional power conferred to them by ISIS over their female relatives and acted on it: 'my husband threatened me with ISIS. He always said: 'if you don't shut your mouth, I will tell ISIS that you are not a good woman and I will let them to take you' (Hassan Sham camp, KII, Female).

These different quotes show the complex impact on gender relations within households brought about by ISIS's occupation of territory. Humanitarian actors need to acknowledge the effect on intra-household power relations, programming in such a way as to avoid exacerbating or fuelling tensions between husbands and wives. In particular women's rights, women's economic empowerment and gender justice programming (which are to be considered a priority) need to ensure the buy-in of men (without asserting male authorityl in order to effectively advance positive effects on women's lives.

\section{Involuntary, coerced and early marriage}

Another impact of ISIS occupation on households relates to the increase in early marriage as a coping strategy. The rationale for the increase in early marriage lies in the 'fear of criminal acts perpetrated by ISIS' (Jeddah camp, KII, Female). At the same time, narratives also frame 'girls as burden (due to) the inability of parents to protect them and provide a secure place for them' (Salah Al Din, Tikrit, FGD, Female). Despite limited references by study participants to the fate of adolescent and young women, who have been abducted by ISIS, in the course of the validation session, enumerators confirmed instances where 'honour killings' have taken place. The data set from Mosul indicated that $86 \%$ of female respondents from Hassan Sham and $46 \%$ from Jeddah camp reported that the practice of early marriage increased during ISIS occupation. Furthermore, the majority of male and female respondents reported that the age of marriage decreased under ISIS, although this was reported by a higher percentage of women (90\%) than men (69\%).

Despite the known effects of early marriage on girls in relation to health, dropping out of school, and exposure to violence, this practice was often framed as a 'safe' coping strategy in the narratives of female and male study participants, particularly when marrying daughters to their cousins: 'Forcing the girls to marry their cousins is a safe coping mechanism as the girl would be saved from marrying 
an IS member. More importantly, it does not imply a loss of decision-making power. It is culturally accepted and preferred for girls to marry a cousin' (Hassan Sham, KII, Male). This pattern is consistent with findings from Salah Al Din where the 'safety' of this coping mechanism was also stressed (Salah Al Din, Tikrit, FGD, Female). The validation session also yielded that, for conflict-affected families, it was preferable to marry daughters into polygamous households because of the reduced number of 'available' men and study participants did not want their daughters to marry ISIS members. Under such circumstances, being a second wife appears to be preferable than becoming the wife of an ISIS fighter.

However, there are also references to parents marrying daughters to ISIS members in order to ensure safety, access to services and livelihood opportunities for the entire family. Study participants reported that adolescent and young women faced involuntary marriage, as their brothers, uncles or fathers would join ISIS and force them to marry someone in ISIS. While there are recurrent references to women being able to fast-track divorce procedures as ISIS husbands left, these adolescent and young women continue to face increased stigmatisation for perceived affiliation with ISIS, as will be explored further below.

\section{Household tensions and domestic violence}

In response to the disruption of the social fabric, the retraction of safe public space, the conflictinduced disintegration of household units and the regulation of marriages, household members increasingly withdrew to the domestic space, which resulted in increased household tensions. Reported household tensions are pervasive. A female study participant from Anbar governorate recounted in the interview a list of household related conflicts: 'Conflicts between brothers in the family, conflicts between the father and sons in the family, conflicts between neighbours, conflicts between women and conflict between husband and wife' (Anbar, Fallujah, KII, Woman). In Salah Al Din governorate, an increase in household tensions was the third most prevalent conflict affectation (reported by $15 \%$ of $\mathrm{HH}$ survey respondents). Interestingly only $7 \%$ of women, in contrast to $19 \%$ of male respondents, reported increased household tensions. Arguably this forced enclosure in the domestic space was perceived as a greater rupture for male respondents than for female ones. Comparatively, in Anbar governorate data indicate that women are most likely to report increased tensions in the household $165 \%$ compared to $38 \%$ of men), as well as IDPs (53\% compared to Remainees at only $14 \%$ ) and urban respondents $148 \%$ compared to $38 \%$ rural respondents).

Female and male study participants across all three locations associate increased household tensions with a higher prevalence of domestic and intimate partner violence, usually committed by adult male household members as a result of 'pressures on the head of the family to provide for the household due to the lack of job opportunities' (Anbar, KII, Woman). Across the three locations, women and children were identified as those primarily affected by domestic and intimate partner violence, which is conceived as a continuation of conflict-induced violence waging at community level and beyond, as a female study participant from Anbar explains:

Women and children have suffered most in this conflict, due to areal bombardment, the threat and intimidation by terrorist gangs, the fear of being killed. In addition, the head of the family often turned violent towards his family, beating his children and his wife, without any reason whatsoever (Anbar, Ramadi, KII, Woman).

This quote indicates that study participants frame the increase in domestic and intimate partner violence as yet another expression of the armed conflict. Linking the increase of domestic and intimate partner violence to the prevalence of armed conflict (instead of considering it a private matter) allows humanitarian and recovery practitioners to see how men's perceived failures to live up to gendered expectations as income providers has resulted in men compensating by resorting to violence. Findings from Oxfam's Gender Analysis in Diyala and Kirkuk also apply to the three study locations analysed in this research: 'In those cases where men are not able to fulfil cultural expectations in terms of providing for their family, there is a significant increase in what women termed 'frustration' and 'anger'. This has resulted in men abusing those who they perceive as weaker - their wives - in order to reassert their masculinity' (Oxfam 2016a:4). Domestic violence is further exacerbated by the lack of livelihoods opportunities, as well as confinement inside homes. 
In instances where women depend solely on their abusive husbands, attempts to commit suicide have been noted by women interviewed in this research across different study locations: 'I heard of many women who tried to kill themselves because of the beatings of her husband (Jeddah camp, KII, Woman). Furthermore, 'it is very difficult for women to get rid of the violence, especially if the reason is her husband or one of her family members. Therefore, we find a lot of suicides and girls running away' (Salah Al Din, Tikrit, KII, Woman). Study participants and enumerators also referred to other coping mechanisms, such as an increase in the prevalence of divorce, despite the high social cost and resulting stigmatisation. However, quantitative data gathered does not indicate a significant trend.

\subsection{SHIFTS IN GENDER NORMS DURING ISIS OCCUPATION}

This section explores shifts in gender norms by analysing the perceptions of study participants in Anbar, Salah Al Din, and Nineveh. As a fairly abstract concept, gender norms are understood in this research as attitudes and beliefs held by individuals about socially accepted ways of being female and being male in a particular context and the social pressures women, girls, men and boys experience to comply to those gendered expectations. Furthermore, it is important to distinguish between norms and people's actual behaviours: whereas norms describe social pressures to behave in a certain way, people's behaviours (how they act or conduct themselves) do not always conform to those norms. The cost of not conforming to gender norms varies, but can be high, including shaming and social exclusion, violence and even death (Saferworld, 2016:2). A better understanding of gender norms, in particular those driving conflict and insecurity and those building trust and social cohesion, has the potential to positively impact on the quality of humanitarian and recovery interventions.

Gender norms are flexible social constructs and do change over time - in the course of armed conflict, gender norms may often change faster. There are inherent challenges to map shifts in gender relations: among them the acknowledgement that ISIS occupation (the focus of this research) constitutes one additional element in recurrent conflict cycles in Iraq. Furthermore, as study participants currently experiencing displacement reported, the conflict is not yet over and is likely to affect generations to come. Consequently, a clear distinction between gender norms in pre-ISIS, during ISIS and post-ISIS is not possible. This research contributes discernible trends that can help humanitarian and recovery actors to operate in a gender-responsive and conflict-sensitive manner to mitigate, rather than fuel, gender norms that underlie conflict. Moreover, study participants are not a homogenous group of people and they have been affected differently by recurrent cycles of armed conflict lincluding ISIS occupation) in accordance to their background, gender, age, ethnicity and civil status. Finally, it is important to note that this research explores the perception of study participants, who experienced occupation under ISIS rule and are currently living in contexts of displacement. Therefore, their accounts are carefully framed to avoid directly implicating themselves and their family networks as associated to ISIS. Further research is required to capture shifts in gender norms among people who voluntarily joined ISIS and agreed with ISIS's worldview.

The following section explores the prevailing gender norms, beliefs and attitudes held by study participants, in order to contrast them with ISIS's imposition of gendered rules in the course of their occupation.

\section{Prevailing gender norms}

Study participants from Anbar, Salah Al Din and Nineveh describe their prevailing beliefs and attitudes around gender norms as based on intrinsic differences between women and men. Expectations of gendered behaviour are based on deeply ingrained gendered division of labour and centre on the roles of men as providers and protectors linked to responsibility as head of household, while the role of women is associated to domestic and careresponsibilities.

In qualitative data gathering sessions, study 
participants were asked about idealised constructions of femininity and masculinity, concretely, what it means to be a 'good' and 'respected' woman and a 'good' and 'respected' man in their communities. The table below shows the most prevalent answers from the three study locations:

\section{Table 3.1: Idealised qualities, traits and practices of femininity and masculinity}

\begin{tabular}{|l|l|}
\hline Idealised qualities and traits of femininity & Idealised qualities and traits of masculinity \\
\hline Respects elders, obeys parents and husband & Responsible for the wellbeing of his family \\
Should be married before she reaches 20 & Protects the home \\
Commitment to traditions and habits, serious & Provides safety for his children \\
Takes care of husband, home and children & Educated, with a degree \\
Responsible and committed to family & Traditional values \\
Able to raise a family & Wisdom and rationality \\
Polite and good personality & Generous and moderate \\
Strong & Be against ISIS \\
Doesn't mix with unrelated men & Wealthy \\
Moderate in dress, covers her hair & Good looks, well dressed \\
Educated and literate & Confident \\
Has a nice figure, good looks & In high position of society \\
& Respects others, has good morals \\
& Does not hurt anyone \\
& Has respect for women, treats women well \\
& Helps in the community \\
Communicates with relatives
\end{tabular}

The table of idealised traits above describes the importance of the household unit, linked to the wellbeing of the family and the importance of marriage as civil status. Idealised notions of femininity describe the gendered expectations for women to be dedicated to the domestic realm and have the capacity to raise a family, while observing socially accepted rules of modesty, respect and traditions. Idealised notions of masculinity describe gendered expectations in terms of providing for the wellbeing of the family unit, with a particular focus on protection and safety. It is noteworthy that study participants associate notions of idealised masculinity with 'being against ISIS'.

When contrasting idealised gender constructions of lived experiences of study participants interesting variations emerge. Despite idealised traits of femininity and masculinity being rooted in complementary difference and focused on the wellbeing of the family units, in practice female study participants do play roles outside the confines of the domestic space. Another constraint to live up to gendered expectations of femininity relates to the importance of education among women, which is limited because of recurrent cycles of armed conflict and the resultant breakdown of the school system, as will be addressed below. Study participants are also aware of the gender norms that constrain husbands from engaging in housework without social stigmatisation:

I wake up in the morning, pray and serve breakfast to my children. Before ISIS we had work, as electricians and carpenters, but now we haven't any work. While some men help their wives in the housework, my husband does not help me, because he is afraid of gossip, because in our community it is not accepted for a husband to help his wife, so she didn't want her husband to help (Hassan Sham camp, FGD, Women). 
Consequently, the idealised construct of men as providers and protectors of households results in perceived pressures for men not to engage in unpaid care work.

Contrasting idealised features of femininity and masculinity with lived practice also allows the exploration of practices that are stigmatised when enacted by the opposite gender. For example, study participants report that a woman is stigmatised when perceived as not adhering to her role as caregiver in the home. These references emerged related to women taking on paid work outside the home (especially when the husband is not working) and associated with 'women thinking she is more than she is'. Women's efforts to engage outside the home are sometimes interpreted as being disrespectful to the husband, by not fulfilling her duties in the home. In addition, stigmatisation emerges with being perceived as 'excessively feminine', which is easily associated to promiscuity and often relates to the way women dress lattire that is perceived as too exposing or seen as vain, trying to show herself off). Finally, women are perceived to be stepping outside of the confines of gendered behavioural norms when perceived as being too demanding. For example, when women make requests or demands, such as going places or speaking when not spoken to. This extends also to the community level, as the following quote shows: 'I am afraid to request anything from my community because my community will look to me in a bad way. I will be considered a 'rebellious woman' (Hassan Sham camp, KII, Woman). Qualitative data further suggest the importance of peer pressure of women on other women in order to ensure compliance. The Mosul data set asks 'what happens if the person does not have these qualities?' and recurrent references of female respondents relate to women's efforts to speak to other women, 'convince them' and 'providing advice' in order to 'make them change', i.e. comply.

In contrast, men are stigmatised for being too permissive with their families, which is associated to a lack of control and can be perceived as being less manly. This includes references to permitting festivities in their homes or listening to (loud) music. Other references point towards transgressing their expected gendered behaviour as men when being supportive in the household and engaging in domestic work that goes beyond repairing and improving the house. What is notable is that failure to live up to idealised gendered expectations of masculinity in terms of 'not hurting anyone', 'respecting women' or 'having good morals' does not emerge from qualitative data as resulting in stigmatisation of men. Arguably, study participants regard domestic violence Iwhich is exacerbated in the course of ISIS occupation, as will be addressed below) as a private matter and condoned within the role of head of household to 'maintain control'. Study participants report that intimate partner violence perpetrated by men can result in stigmatisation and reprimand, as highlighted in the following quote: 'the tribal society does not accept such a man. They will first speak to him and provide advice to him and his family and in case of not responding it will lead to his detention at the Sheik's house' (Anbar, Khalidya, FGD, Male). However, it appears that a man that beats his wife is not considered less manly, despite contradicting the idealised notions of masculinity. This points to the differential enforcement of idealised gender constructions in daily practice and the pattern that women have to navigate narrow confines of socially accepted behaviour that is more readily stigmatised, unlike perceived transgressions of their male peers, which speaks also to women's subordinate position.

According to study participants, women are also exposed to a more repressive system of social sanctions when failing to comply with socially accepted gender norms, which are also more strictly enforced and comprehensively punished in comparison to their male peers. Examples of social sanctioning of women's practices perceived as transgressions are highlighted in the following quotes: 'she will lose her job and is looked at in a negative way' (Anbar, Fallujah, FGD, Male); 'she will be exposed to criticism and insult' (Salah Al Din, Baiji, KII, Female) and 'subjected to abuse and humiliation' (Salah A Din, Baiji, FGD, Female). Other punishment results in her and her family being sent away from the area (Anbar, Khalidya, FGD, Male). A distinctively gendered mechanism of enforcing control is violence, bodily harm and assassination: 'it is possible that women are subjected to violence if they do not abide by norms' (Anbar Khalidya FGD, Women), or 'banishing the woman from the community and depriving her of all her rights' (Anbar, Fallujah, KII, Woman). Probing further into bodily harm and attacks on physical integrity women and men coincide: 'the penalty is 
killing and honour crime' (Anbar, Fallujah, KII, Woman), which also emerges in another district in Anbar: 'in case of reccurrence, the lack of compliance to norms, results in death, or honour killing' (Anbar Khalidya, FGD, Male).

In contrast, a pattern emerges in the responses of female study participants that indicates a lack of punishment against men who fail to comply with idealised notions of masculinity:

Nothing will happen to them, because there is no punishment of men in our community. Especially if those men have a lot of money, nothing will happen to him and everyone will give excuses. No one will punish him. Because he is a man and he is in his right. Our community forgives the men and punishes the women (Jeddah camp, KII, Female).

Men's exemption from punishment also emerges in the following quotes from other locations: 'Men do not face any punishment, because the community we are living in prefers the man over the woman' (Salah Al Din, Baiji, FGD, Women). Nonetheless, dissenting opinions have also been registered, particularly when women report that men who face a 'lack of respect from their community' (Salah Al Din, Baiji, KII, Woman), 'would be looked with total contempt, considered outcasts by society. He will be humiliated, and sometimes even subjected to physical assault' (Salah Al Din, Tikrit, KII, Woman), or 'he will be constrained in his movement and exposed to insult and verbal and physical violence' (Salah Al Din, Tikrit, FGD, Female).

However, men's responses consistently stress being subjected to sanctions for their failure to comply with gendered norms, in particular those related to the perceived transgression of 'being against ISIS'. In male study participants' perception: 'men get rejected by the community, no one will deal with him, he even gets banished and will leave the neighbourhood' (Jeddah camp, KII, Male), 'all social connections will be cut with the man to isolate him from society' (Hassan Sham, KII, Male), or 'the community loses trust in that person and he loses respect in the community's perception' (Anbar, Fallujah, FGD, Male). While the enforcement of gender norms varies in accordance with the local context, as they rely on control by local authorities, the main practice is ostracising those non-conforming men, while at times resulting in verbal and physical violence.

\section{Imposition of radicalised gendered norms during ISIS occupation}

In the effort to install the caliphate, ISIS introduced and enforced fundamentalist gender conceptions of accepted femininity and masculinity that were translated into daily practice by a distinct set of gendered behavioural rules that were interpreted by study participants as a radicalisation of prevailing gender norms.

While women in pre-ISIS settings felt bound by rules of modesty, wearing headscarves with theirfaces showing and coloured clothing (HRW 2016), ISIS introduced strict rules around women's attire, including wearing the Niqab in public (black and without decoration), including socks and gloves and avoiding tight dresses. Male study participants perceive a considerable loss of power within the household due to imposition of the ISIS dress-codes on their wives: 'When the conflict happened and ISIS forced the women to wear the Niqab and gloves and forced other rules on them. Those who resisted were punished, severely punished. Although the husband didn't agree with ISIS he complied with their rules out of fear' (Hassan Sham, FGD, Women). This quote relates to men being coerced into enforcing ISIS's rules within their own households under the threat of paying fines, public humiliation and bodily harm.

Furthermore, women were not allowed to go to public spaces on their own, and were effectively prevented from going to the market or taking a taxi without a male relative. Further restraints included the rules to only be attended by a female shopkeeper, which significantly curtailed women's options. Female study participants also report not being allowed to speak loudly, or to wear make-up.

In contrast, dressing norms for men include short trousers (the Afghan attire), they were forbidden to shave and were pressured into having a beard and long hair. While male study participants could go to public spaces (despite potential harassment at checkpoints), they were not allowed to gather on street-corners to smoke and chat to neighbours and friends, as they were used to doing before ISIS occupation. Selling and buying cigarettes, as well as consuming alcoholic beverages, were forbidden. The use of mobile phones, the use of internet, listening to music, and chewing gum were all banned. In addition, men report being coerced to pray at specific times and to attend the mosque on Fridays. 
Perceived transgressions against the rules were punished: 'My brother was taken to prison and has been punished by digging graves and he had to pay a fine of 250,000 Iraqi dinars, because he did not abide by wearing short dress' (Hassan Sham, FGD, Women). Another reference also relates to being fined: 'at the praying call, one had to be at the mosque, otherwise ISIS would impose a fine' (Jeddah camp, FGD, Women). These rules enforced compliance often through brutal corporal punishment, also against children: 'My daughter (she was 12 years old at the time) went outside to wash something in the garage and ISIS punished her by beating her, because she went outside and she didn't wear the veil so I begged them not to hurt her and they took money, about 50,000 Iraqi Dinars' (Hassan Sham camp, KII, Female). Furthermore, fines were imposed for not adhering to gender norms regarding attire.

Male and female study participants agree that ISIS's attempt to impose new rules about attire, behaviour and practices constituted a radicalisation of prevailing gender norms. While many of the study participants did not agree, they were coerced into complying with these rules. There are limited references to buy-in to these new norms. However, according to study participants, ISIS's radicalised gendered conceptions did not imply a long-term reversal of prevailing gender norms. Instead, female and male study participants reported a return to usual behaviours and practices as soon as ISIS retreated. Examples include men shaving their beards and cutting their hair las has also been reported through international news outlets) and where possible to return to wear long trousers. Male study participants from Mosul refer to feeling uncomfortable having to continue to use short trousers for lack of alternatives. Similarly, female respondents report that most women in their communities have reverted to wearing a headscarf instead of the Niqab, and argue that some of those who continue to use the veil do so out of concerns relating to possible infiltration of ISIS members in the camps, ${ }^{17}$ indicating that study participants continue to aim to live up to pre-Daesh gender norms in a context of displacement.

\section{Attempts to comply to gendered norms of masculinity}

Under ISIS occupation, male study participants report of constraints in living up to gendered expectations as income providers for their families, especially for men who refuse to join ISIS. Concrete references comprise constraints to access livelihood options, deprivation of livelihood options, such as heavy regulation of jobs (so they are only available to ISIS members) or the closure of businesses, such as beauty salons and barber shops that countered ISIS ideology. Furthermore, in the course of the armed conflict study participants lost assets, access to land (for farmers), or access to their workplaces because of movement restrictions and roadblocks implemented by ISIS. ${ }^{18}$ Study participants clearly link conflict effects with social pressures on men: 'There is more violence towards men, they are prevented from doing many things they used to do. Men are also affected by the conflict for thinking all the time how to provide income for the family' (Hassan Sham, KII, Woman).

Another aspect of loss of power as head of household relates to sons joining ISIS voluntarily, replacing fathers as the household provider and consequently taking over decision-making power within the household. There were references to sons denouncing their fathers for perceived lack of compliance with ISIS's rule resulting in the punishment, and abduction of the accused.

While men's capacity to live up to gendered expectations as providers has been significantly constrained during ISIS occupation, and continues in contexts of displacement, male study participants were able, at least in part, to live up to gender norms as protectors. Study participants report trying to live up to gendered expectations of protectors referring to enforcing movement restrictions on household members, in particular wives and daughters. This is mostly achieved by ensuring household members comply with staying indoors. This practice emerges across the different governorates, in both urban and rural settings. Examples include: 'Most of the time I would keep my family inside to avoid Daesh' (Hassan Sham, Male). An example from Jeddah host community relates to a practice of protection by covering the house with a large piece of cloth, in order to shield the family from view of Daesh (Jeddah camp, KII, Man), allowing his daughters to move outside the confine of the house without being seen from the outside.

Male study participants regard the provision of safety for the household as means to live up to gendered expectations. Several references consider

17. In one of the FGDs in Jeddah camp, one young female study participant expressed that she opts to continue to use the Niqab because she got used to it and feels comfortable wearing it.

18. In Salah Al Din, 37\% of men report movement restriction as exacerbating vulnerability, in comparison to $13 \%$ of women who report the same. 
it an accomplishment and pride to have been able to 'lead families to a safe place', 'get families away from aggression', and to 'provide a safe haven'.

\section{Attempts to comply to gender norms of femininity}

Despite the fact that women have engaged in paid work outside the home before ${ }^{19}$, during ISIS occupation women's capacity to generate income was constrained by movement restrictions. As a woman living in Hassan Sham explains: 'I had to give up my job at the University of Mosul, because the work of women is forbidden under the rule of Daesh. Also for fear for my life and the lives of my family members, I had to leave my job in order to avoid violence from Daesh' (Hassan Sham, KII, Female). A similar example emerges in rural contexts, where women were prevented to work in the fields or engage in farm work (Salah Al Din, Tikrit, KII, Woman).

The strict segregation of women and men in public space, results in women being largely confined to the domestic space during ISIS occupation. However, women still strive to live up to gendered expectations of femininity and do so by extending their understanding of 'ensuring the wellbeing of their family' to include 'protecting their families' through their care roles. To the extend possible, women act as protectors imposing movement restrictions on her children: 'women do not allow her children to leave the house, because they want to prevent them from joining Daesh' (Jeddah camp, FGD, Women) or 'not letting her children socialise with armed groups that have caused conflict' (Anbar, Khalidya, FGD, Men). Women's contribution is also framed as 'protector of families and children from the brutality of terrorist group (Anbar, Khalidya, FGD, Female). Other references to the roles women play as protectors relate to 'keeping the family united' (Anbar, Falluja, KII, Woman), 'preventing family separations' (Anbar, Falluja, FGD, Male) and maintaining 'control over children' (Salah Al Din, Tikrit, KII, Woman). Consequently, the role women play on the household level is acknowledged and may also serve as entry point to enhance more active citizenship at community level:

Women had important role in our communities during the conflict by watching over family members, especially youth and children, through the provision of psychological support and increase self-confidence of children for them to stay away from Daesh (Anbar, Heet, FGD, Female).

Another way women have taken proactive roles, while living up to gendered expectations as care-givers, relates to insisting on education for their children, in contexts where the school system was put at the service of ISIS's worldview. Examples thereof, include women's role in '...supporting their sons and daughters in their education and their studies and pushing their children so that they do not lose the opportunity of education' (Anbar, Ramadi, FGD, Male). The encouragement and motivation of children to continue learning is stressed ISalah Al Din, Samarra, KII, Man). In addition, women are seen as having a role to play in teaching her children 'skills of dialogue, insisting in educational work, to guide children, and to provide advice' (Hassan Sham, KII, Female) and 'help children of the community to distinguish between right and wrong, as well as raising awareness of the risk of conflict for the community and its negative impact on the society more generally' (Anbar, Ramadi, FGD, Female). This relates to a sense of women's roles as providing protection through education (Salah Al Din, Baiji, KII, Woman) and encouraging children to learn (Anbar, Heet, FGD, Female).

Despite significant constraints women face during ISIS occupation in terms of restriction of their roles of providers, female study participants report aiming to comply with gendered expectations of femininity under Daesh occupation by extending their understanding of the domestic space positioning themselves as protectors and as educators. The enhanced role of women within the domestic space was not framed as undermining the power of the head of household, but as contribution to the household, which was also acknowledged by men. For example, 'women gave their best effort in order to protect their families, relatives and loved ones. Also when women participated in the joint decision-making with the men in the course of displacement and when contributing to finding means of livelihood' (Anbar, Ramadi, FGD, Male). These references indicate an entry-point to further the incipient acknowledgement of women's vital role in keeping children safe, while enhancing proactive roles on a community level.

19. Documented examples thereof include references to women working in private companies, factories, stores (urban areas) and dairy production and as agricultural workers (rural areas). Their livelihoods depend on their location (urban or rural) and the decision in the household for her to work or not leach family may have made different decisions before ISIS occupation). 


\subsection{RECONFIGURATION OF GENDER RELATIONS IN CONTEXTS OF DISPLACEMENT}

Despite the fact that ISIS's attempt to install fundamentalist gender conceptions was perceived as temporary, current practices in displacement settings suggest an ongoing re-negotiation of gender roles and responsibilities. This relates to conflict-related impacts on communities and households, current circumstances in displacement settings and concerns around longer term shifts in livelihood options (decrease in industrialisation, less viable local agriculture options or job creation in the context of reconstruction) that arguably will lead to shifts in gendered division of labour and will generate opportunities to re-negotiate power relations at household and community levels. Consequently, rationales based on 'culture' or 'traditions' are likely to undergo scrutiny and pressures for women to contribute to the household income to increase, which may generate opportunities for women to increasingly enter the paid workforce.

\section{Increased competition for livelihoods}

In the context of displacement, access to viable and long-term livelihood options is limited and competition for available income generating opportunities is fierce among IDPs, Returnees and Remainees. Furthermore, location specific challenges arise, as for example study participants in Hassan Sham camp report not being able to leave the camp, while in Jeddah camp, men's predominant concern evolves around the fact that there are no available jobs. As Oxfam's gender analysis (2016a) notes, prior to displacement, men were responsible for generating income and fulfilment of this responsibility accorded them power and respect. However, since displacement, not only are men 'bored' and with 'nothing to do', they also reported feeling shame and powerlessness.

Male study participants reported increased pressure to live up to gendered expectations as income provider, in a contexts where tensions arise around whether men's roles are perceived as predominant income provider (pre-ISIS) or sole income provider (during ISIS) is negotiated. The perception of men as sole providers of households can only be maintained at high personal cost and increasing frustration among young and adult men, especially once security concerns are reduced.

While some men show disposition for women to resume paid work outside the home, this dynamic needs to be analysed against the backdrop of an overall loss in men's capacity to live up to their expected gender roles. Primary data from this study shows on the one hand women are willing to engage in paid labour outside the house, 'doing anything' in order to support the household. However, female study participants also indicated a series of challenges in order to ensure their involvement in paid work outside the more. These barriers include either having too much household responsibilities or lack of consent from their husbands due to perceived inappropriateness in accordance with cultural norms. In Salah Al Din, factories, beauty centres, offices and dairy farming, knitting and sewing are all listed regularly as accepted activities. Furthermore, Oxfam programming in Diyala and Kirkuk shows that backyard farming, rearing cattle and chickens that do not require grazing, dairy production; and homebased businesses, particularly where in-kind provision is possible, are also acceptable livelihoods options. There is a preference for work that women can do inside or close to home. 'Women can work but at a lower rate than men, as they have housework to do as well. The MSNA dataset also indicated that safe space for women could be organised around sewing workshops, bakeries or a laboratory so women can work either from home or with other women' (MSNA, FGD on Markets and Livelihoods with women in Salah Al Din, Samarra).

\section{Shifts in decision-making power within the household}

Shifts in decision-making power within the household relate to crisis-induced reduction of household size and severed ties extended family networks and disruption of community constitute generate opportunities to renegotiate gender roles. As a male study participant reports:

Now, people are depending on their personal decision and each family decides for their family, they do not rely on community leaders; they do not have the same values as before, husband and wife will decide on their family not like before, the mother of the husband, who used to distribute the roles in the family and deciding behalf of all of them (Jeddah, host community, KII, Man). 
Household survey data indicated that $71 \%$ of respondents in Salah Al Din and 62\% of respondents in Anbar report to feel safe where they are currently living 20 . The most common reported factor creating perceptions of safety was the presence of family and relatives, confirming that the household (despite increased levels of household tensions) is a source of protection, a pattern that emerges in the course of different questions around willingness to stay or decisions to move: 'my family is here/there'. With regards to the question 'how do you try to provide protection to your family?', female respondents in Anbar report 'living with my family' (53\%), 'living near my relatives' (44\%) and living near people I trust (38\%) as the most prevalent answers. Living with my family also ranked high among male respondents (52\%) followed by living close to a place they could find livelihoods (50\% and living near their relatives (50\%). This trend also emerges in Salah Al Din governorate.

An interesting reference emerged around women's perception of increased decision-making power due to more limited relations with the extended family, which correlates with the perceived loss of power and influence of the mother-in-law: 'Before ISI, my mother decided for me and my wives. All the wives depended on her decision for everything related to the house until she died' (Jeddah host community, KII, Man). While the physical separation from the mother-in-law may constitute a source of increased agency of wives, Oxfam's Gender Analysis also suggests that with the reduction of influence of the mother-in-law, her sons are also less compelled to consult their mothers on their decisions, a practice that was prevalent before the conflict.

Furthermore, widows, who are often portrayed only in terms of their vulnerability also reported an increase in decision-making power, despite the hardship and stigmatisation they face: 'After conflict women have more decision making power especially women who lost their husbands (widows). They became responsible for their family or the families that lost the eldest son. They are women who are able to make decisions and have the ability to contribute in the various fields (Anbar, Heet, FGD, Female). Another female study participant from Anbar stresses: 'Some women have become decisions makers, especially women who lost their husbands and became responsible for their families (Anbar, Heet, FGD, Female). This last reference also confirms findings of Oxfam's gender analysis (2016) that stresses the perception of younger women in Diyala and Kirkuk that marriage is an obstacle for women's education, economic empowerment and decision-making.

These shifts in power relations within the household generate opportunities to re-negotiate gender roles, as study participants refer to improved bonding within households, due to shared suffering in the course of ISIS occupation:

'Men are involving wives more into their decisionmaking, because both of them they have learnt from the conflict, or the difficulties, women and men each have their role now, as the conflict more clearly ISIS discovers all the realities to people like electric shock made all wake up (Jeddah Host community, KII, Male).'

Other references describe a 'better and stronger relationship in comparison to before the conflict as a result of their participation and solving problems' (Anbar, Falluja, FGD, Male).

References to improved bonding within households during displacement correlates female study participants' perceptions that there is an increase in women's decision-making power in the course of displacement. For example: 'most of the decisions in the house are now made by women and they have the capacity to do so. They control household expenditure and also plan the household budget, and they also have decision-making power for anything concerning their children, such as marriage, health and education' (Anbar, Heet, FGD Female). Similarly, in Salah Al Din a female study participant reported: 'I have more capacity to make decisions and more say on how to raise the children and how money is spent' (Salah Al Din, Baiji, FGD, Female).

However, there are also dissenting opinions among male study participants: 'Men think that women have more authority now, but they don't give them any role and limit the duties of women to food preparation, education of children and to arrange the tent or shelter (Anbar, Ramadi, FGD, Male), while another Focus Group participant described a backlash: 'Yes, men think that women have far more decision-making authority. Men do not believe that women should be involved in decisions on how to spend money at home' (Anbar, Ramadi, FGD, Male). This pattern also emerged in references to expectations that women should

20. In both governorates, respondents of rural origin were more likely not to feel safe. For example, in Anbar, $72 \%$ of rural respondents report not feeling safe in comparison to $32 \%$ of urban origin, which report the same. 
resume their subordinate positions and support at best the head of household. When asked about the possible roles of women references are made to for women to 'engage in constructive social activities that generate trust and supporting men in the home and help them make decisions' (Anbar, Falluja, FGD, Male) and expect women to be 'patient, obedient, and should try to help her husband, support him, in a nice way not rough and strong way, because man needs soft woman to be patient' (Jeddah, KII, Male).

This section has shown how constraints to live up to gendered expectations may create opportunity for shifts (albeit small) to renegotiate gender roles within the household, however it also highlight that there are also attempts to undermine women's increased participation.

\section{Women's disposition to engage more in community level decision-making}

Community level decision-making structure are male dominated, which in turn constrains women's and girls' ability to systematically engage in the identification and provision of humanitarian services (IASC 2014): 'the men solve problems and make decisions. There is no participation of women in it, if so, very rarely' (Anbar, Fallujah, FGD, Male). Concurrently, Oxfam's Gender Research (2016) further shows that in Kalar over $90 \%$ of female respondents did not participate in local decision-making, which is also confirmed by female study participants: 'Women in our society are non-existent in making decisions and solving problems, because our societies are used to men making decisions' (Anbar, Heet, FGD, Women). This points to limited spaces of civil society organisations at the local level, which are a prerequisite for active citizenship and would require a concerted governance work by humanitarian and development actors.

Opportunities to engage in enhancing civic spaces at community level emerge in references made by female study participants stating that women should participate in community decision-making, although in practice they rarely do. The Mosul survey asked study participants whether they felt they have a role to play in solving major problems and challenges in their communities upon return. In Hassan Shan camp, $63 \%$ of female study respondents said yes, compared with $87 \%$ in Jeddah camp. Male respondents were $83 \%$ in Hassan Sham camp and 65\% in Jeddah camp.
The women's FGD in Heet district in Anbar governorate suggested that educated women and those with a strong personality are the women who should be participating. At the same time, female respondents also link men earning a living with the potential for women to take up more active participation at the community level (Anbar, Khalidya, FGD, Women). This may be that, as men are able to fulfil their expected gender role as provider for their family, there is no threat to their masculinity if their wives contribute to the family as well. This would allow both men and women to provide for their families without taking from the man his expected role. Furthermore, female participants request awareness-raising sessions and capacity-building for some of the women who have a role in community (Anbar, Khalidya, FGD, Women)

Despite the expressed interest in participating in community decision-making, female study participants are also aware of the cultural constraints that keep women from participating in community discussions (0xfam, 2016a). 'The women have less ability to make the decision-making and because of the nature of the community and the norms and traditions' (Salah Al Din, Baiji, FGD, Female). Other explanations include that responsibilities in the home take up much of their time (Oxfam, 2016a). Female-headed households or divorced women may face additional constraints of accessing or even participating in community level decision-making spaces, due to stigmatisation in relation to marital status. An additional point being raised is the shifts in power and authority within the community, as well as the fact that there are no cohesive communities because of the influx of IDPs and Returnees.

While there is a disposition of women to engage more in community-level decision-making, their participation is contingent on solving priority needs related to livelihood options, as well as concerted efforts to address the perceived cultural constraints.

\section{Increase in unpaid care work for women and men}

The application of Oxfam's Rapid Care Analysis programmes in Iraq, five to date, indicates an increase of unpaid care work ${ }^{21}$ for women and men in contexts of displacement. While multiple factors shape unpaid care work, ${ }^{22}$ women consistently invest more time and energy into this in comparison to men. Men spend only an average of 25 per cent of the total

21. Care work, particularly unpaid care work, refers to activities pursued by a person including all tasks that directly involve family welfare done in service of members of the family and/or community (Oxfam 2017).

22. The intensity and magnitude of care work in terms of time, physical exertion and energies expended by the women is greatly influenced by the number and ages of the children, the financial resources available and the kind of family relationship. The urban or rural setting of family households also greatly shapes the nature of care work provision, as an urban setting would make access to market sand goods, transportation, utilities like piped water and electricity available. Urban dwelling also affords families more exposure to a diversity of information, people, technology and ways of the world (Oxfam RCA, 2017). 
time allocated by both men and women to care work (Oxfam, 2017). Mothers, older (unmarried) daughters and elderly women are the ones that mostly engage in unpaid care work. These findings are confirmed in the course of this research, when female respondents in Hassan Sham camp report that the time spent in unpaid care work increased from 'one to three hours' (49\%) before the conflict to 'most of the day' (52\%) in situations of current displacement. ${ }^{23}$

Research further showed that women in conflictaffected governorates of Iraq regard care work as a fundamental responsibility of a wife and mother and an innate part of her identity (0xfam, 2017). Consequently, researchers identify women's intention to lighten the burden, through shared care-responsibility Idespite the acknowledged stigmatisation of men engaging in what is considered women's work), through child-care facilities and parks or safe places for children play outside lOxfam, 2017), rather than not doing them.

The Rapid Care Methodology also looks at the reported increase of men's unpaid care work, which is linked to movement restrictions and increased engagement of caring for the sick and elderly, often outside the home. In Hassan Sham camp, for the question 'how many hours did you spend taking care of the house and/or children' before the displacement the most prevalent answer was more than three hours (56\%), while the most prevalent answer in displacement is 'most of the day' (87\%). A similar pattern emerges from quantitative data in Jeddah camp.

The shifts in unpaid care work as result of conflict affectations and displacement have the potential to influence broader gendered division of labour. The scale-back of safe public spaces results in the increased relevance of the domestic sphere, which, however, has not (yet) resulted in a general acknowledgement of domestic responsibilities as work (Oxfam, 2016a). Furthering the application of Oxfam's Rapid Care Methodology could be used to raise this awareness and contribute to shared care responsibility, especially when linking idealised qualities of masculinity relating to 'protecting the home' and 'ensuring wellbeing of the family' to unpaid care work.

\section{GENDER NORMS THAT FUEL AND MITIGATE TENSIONS}

This section aims to map out those gender norms that potentially fuel tensions, exacerbate insecurity and increase vulnerability of affected populations; and those gender norms that contribute to build trust, strengthen community cohesion and build resilience. This exploration shows the fluidity of gender norms as they operated in the context of ISIS occupation and persist in displacement settings and include violence in the public, as well as in the private space.

\subsection{GENDER NORMS THAT FUEL TENSIONS, EXACERBATE INSECURITY AND ENHANCE VULNERABILITY \\ Gender norms that maintain men as sole providers of income}

The imposition of radicalised gender norms of masculinity that establish men as sole providers of income have fuelled the conflict as men were pressured to join ISIS in order to secure access to income. The imposition of strict behavioural rules by ISIS, in particular the effective banning of women from the public sphere, constrained women's access to income-generating opportunities and effectively confined them to the domestic sphere. Social pressure on men to provide income 'by any means necessary' coerced men into joining ISIS:

Most people in the community refused ISIS. Even if they avoided to participate in operatives and rejected Daesh 'from their inside'. They really fought against them, but not with guns, people hated Daesh. Only men joined ISIS whose wives forced them or those who needed to access basic goods (Jeddah camp, KII, Male).

Male respondents repeatedly pointed out that their decision to join ISIS resulted from increased pressures from their wives:

Wives forced husband to join ISIS to order to provide for the basic needs of their family. For example, a man was married to three wives and they forced him to join ISIS for financial benefits, and then when ISIS was defeated he was captured. Now they are left with nothing (Jeddah camp, KII, Male).

23. In Diyala, the predominant care work includes child care and food preparation (including baking), cleaning the house and laundry, collecting wood and time used to attend to personal and individual needs of the husband (husband care takes up one of the most number of hours and attention of the women). The most burdensome care work in Diyala is child care, food preparation especially baking, cleaning the house and washing clothes, while in Kirkuk going to market, washing clothes and baking is registered. 
These quotes show the pervasive nature of social pressures on men to provide for their households by any means necessary. Even if being pressured into ISIS constituted an available coping mechanism, this decision fuelled violence in terms of sustaining ISIS's territorial control and human rights abuses, and exacerbating the insecurity of household members if the ISIS members were killed in combat or injured.

In the context of displacement, former allegiances with ISIS result in stigmatisation of the larger kinship structures, even of those members who had no influence over the household member's decision to join. An example relates to a boy whose older brother joined ISIS voluntarily:

They were two members of the household, two brothers, they didn't have a father, only the mother: the older brother joined ISIS and after he was killed the remaining brother - he is 11 years old - was not accepted any more. He is now in Jeddah camp and no one wants him (Jeddah camp, KII, Female).

In general terms, the affiliation of kinship structures to ISIS results from a family member (brother, father) who joined ISIS (even if forced recruitment). If, in a family, the father joined ISIS and the mother divorced him, the children would still be accused of affiliation, as would his sister. This stigmatisation mechanism also affects families whose children joined ISIS against the will of their parents, with the stigma now affecting the whole family unit: 'Yes, there are people who cannot return because of the affiliation of their children' (Salah Al Din, Samarra). Consequently, the diversification of livelihood options would reduce the pressure on men to attempt to comply to gender norms demanding them to be the sole providers and feel pressured to join ISIS to fulfil this.

Furthermore, maintaining the role of men as sole providers of income continues to fuel tensions in the context of displacement where the increased competition for livelihood opportunities between IDPs, Remainees and Returnees exacerbates underlying community tensions. While the MSNA (Oxfam, 2017) indicates that the relations between IDPs, Remainees and Returnees in Anbar and Salah Al Din governorates are largely not reported as tense, the influx of people on the move may shift power balances in host-communities and lead to increased tensions. Potential underlying community tensions dependent on the specific location can result from relations between the displacement groups (IDPSRemainees/host-communities), along Sunni-Shia, and/or ethnic divides (Arabs and Kurds). 


\section{Pressures on young men to conform to expectations to form their own households}

Another gender norm that relates to access to income were pressures, especially on young men, to engage in risky coping strategies. Quantitative research has established that the perceived appropriate age range for young men to get married is $19-24$. When married, newlyweds are expected to set up their own households and live separately from their nuclear families. Study participants referred to pressures on young men to secure sufficient means to marry and form their own families. Armed conflict often puts peoples' life developments on hold and young men are often unable to form their own families. Anecdotes emerged in the course of fieldwork of the increasing frustration among young men who had girlfriends but were not yet able to marry because of financial reasons or because young women were coerced into marrying ISIS fighters. Other references included young men voluntarily joining ISIS in the pursuit of sources of independent income in order to be able to marry. In the current context of displacement the risk relates to young men joining armed opposition groups.

In contexts of displacement, adolescent men were considered the most vulnerable group, according to $62 \%$ of respondents in Anbar governorate and $50 \%$ of respondents in Salah Al Din governorate. In addition to pursuing income to be able to marry, study participants also indicated that adolescent men are tempted by arms and join armed groups or militias because they have not had anything to do in a long time. Female and male study participants alike stressed the importance of targeting adolescent men and boys with tailored programming to keep them from joining armed groups. The extent to which household members exert pressure for marriage becomes evident in requests for livelihood opportunities from humanitarian actors in order to allow young people to get married: 'support them to get married, as some of the young men are still engaged and cannot marry. Also facilitate marriage for widows' (Jeddah host community, KII, Male).

\section{Gender norms that stigmatise women for not being married}

This research has identified the considerable pressures imposed on women to marry in order to be considered respectable members of the community.
Failure to comply with these norms may compromise the 'honour' of the family, in particular male members of households, and consequently increase levels of insecurity and exposure to violence and stigmatisation. The pressure for women to conform to the socially accepted civil status cuts across different age groups, which carries along different expressions of violence against women. As outlined previously, in the context of ISIS occupation the average age of marriage appears to have decreased, as adolescent and young women are coerced into marriage with cousins in order to avoid being married to ISIS fighters, or pressured to marry ISIS members in order to ensure the family network has access to services and livelihoods opportunities. Widows, female heads of household and divorcees experience significant hardship under ISIS rules banning women without a male relative from the public sphere, significantly restricting women's coping mechanisms to provide for their families, which sometimes has resulted in suicide, self-harm or harming people under their care: 'I have heard of a woman. ISIS killed her husband, she had two children and since nobody supported her, she reached very bad state and decided to throw herself and her kids in the river' (Jeddah camp, KII, Female).

In the context of displacement, unmarried women continue to face considerable stigmatisation and do not have equal and equitable access to humanitarian and recovery assistance. The pressures to conform to social norms related to civil status perpetuate the prevalence of early marriage in the context of displacement. In Salah Al Din governorate, adolescent women $(43 \%)$ are considered the second most vulnerable population segment, while in Anbar governorate they constitute the third most vulnerable segment of population (32\%). Qualitative data collection and validation sessions confirmed that this is largely related to either forced or early marriage.

\section{Stigmatisation of women and girls who survived abduction}

This stigmatisation also disproportionately affects adolescent and young women who were coerced into marrying ISIS fighters, formal members or sympathisers. Adolescent and young women are often faced with 'choice-less choices' in the course of armed conflict. In the course of ISIS occupation, 
adolescent women were married to ISIS sympathisers or fighters, sometimes voluntarily and sometimes pressured to do so. There is no apparent difference in perception on whether a woman was forced to marry or was married being underage. Despite the fact that the Iraq government fast tracks divorce procedures women are still stigmatised. They are faced with being stripped of their agency when married, and even when they willingly divorce, it is not perceived as an act of distancing themselves from ISIS; instead it is a stain that ensures continuous ostracising from the community. There are references to women who where married to ISIS members and had children from those relationships being particularly targeted, afraid of letting the child go outside.

Secondary data also points to the stigmatisation of women or girls who have been abducted by ISIS. It is widely assumed that these women have been subjected to sexual violence, and even if they are able to escape, they face stigmatisation and are at risk of sexual violence or being subjected to honour killings after they flee (IWHR, MADRE and OWFI, 2015). Reports have also emerged of women committing suicide after being abducted by ISIS and raped 'because they couldn't stand the shame' they would bring to their families and communities (IWHR, MADRE, OWFI, 2015). In the larger context of women being considered addons to male family members, external assignation appears to override individual acts (such as divorce), undermining attempts to overcome stigmatisation. While more research is required into concrete stigmatisation mechanisms lincluding prevalence of honour killings), humanitarian actors need to be aware of this gendered dynamic, since singling out women who have been coerced into marriage or those abducted for humanitarian assistance may also result in backlash against these women, as well as fuelling community tensions.

\subsection{GENDER NORMS THAT MITIGATE TENSIONS Men's roles as community protectors}

This research indicates that idealised constructions of masculinity value contributions to the community and the expressed motivation of male study participants to be involved in reconstruction efforts within the community, both in terms of infrastructure and social fabric. This also links in to the perceived responsibility as protector extending from the household level to the community level: 'men can contribute to building trust by identifying strangers arriving in the community and informing security authorities' (Hassan Sham, KII, Woman) or the perceived role of being 'the eyes of the security services' (Anbar, Heet, KII, Man). In the context of displacement, study participants consistently frame the PMF militia not as fuelling the conflict, but as being a contribution to build trust at the community level. Their association with armed groups in contexts of displacement is framed as a measure of strengthening the community through protection. Study participants frame joining armed militias in the context of displacement, not as fuelling conflict, but as contributing to building trust, and as 'waging war to secure peace'.

Furthermore, in the context of displacement, female study participants perceived men's role as protectors of households in terms of reducing tensions at community level. When asked about the roles men can play in the community to reduce tensions a female study participant suggested: 'to reduce the hatred between people in order to avoid dangerous incidents in our community (Jeddah camp, KII, Female), while a male study participant suggests: 'to avoid conflict at any costs, welcoming the help of foreigners (NGOs) and accepting different ideas' (Jeddah camp, KII, Man). The women's FGD in Ramadi (Anbar governorate) suggested restraint in the sense of avoiding the escalation of "'small tensions that might generate long-term conflict; stressed the need to make concessions and show goodwill between different groups in order to strengthen community ties and reduce gaps that generate tensions and conflict'."

\section{Men's engagement as role models for younger generations}

In the context of displacement, beliefs and attitudes emerged that stress the potential of men as role models for younger generations and to lead by example. 'Men need to protect their families from violence and meet the needs of the family and take them out of the home to parks in order to get away from problem and stress (Jeddah host community, KII, Male). Other male study participants recognised the need for men to serve as role models and to contribute towards children's education in order to provide the prospect of a future, while undermining 
motivations of adolescent men to join the PMF to earn an income. In the same vein, other study participants propose 'to support education efforts, help others and fight corruption' (Salaha Al Din, Samarra, KII, Man) and 'for young people to work alongside adults to build a state together for a better future for all. Adults and elderly should be role models for young people' (Hassan Sham camp, KII, Man). Another entry point for adults to serve as role models involves 'gathering young people and encourage them to do sports, manual labour and spend time with their loved ones and families' (Anbar, Ramadi camp, FGD, Female).

\section{Women's role as educators preventing and countering violent extremism}

This research has shown that the particular ISIS occupation resulted in a scaling back of the public space and confinement within the homes associated with safety (despite important levels of domestic violence). In this context, women were able to carve out spaces of meaningful contribution to the protection of the household units through their role as informal 'educators' in the context of school closures or because schools became inaccessible or were ruled out as an option by the families. This space provided to women could be taken to the community level in efforts to ensure that women play a more active role in the prevention of the radicalisation and violent extremism of youth and based on a civilian peace-building agenda, as suggested in UN Women's Global Study on the Implementation of UN SCR 1325 IUN Women, 2015). However, this needs to be carefully thought through in order to mitigate the risks associated with these interventions, such as further emphasising women's home-based role and further confining them to the domestic sphere; undermining the legitimacy and the duty of state-led processes to ensure the implementation of the Iraqi National Action Plan on Women, Peace and Security; gearing the efforts of women's rights groups and donor contributions towards solely community-based programming that is necessary, but not sufficient; and lastly make the prevention and countering of violent extremism the sole-responsibility of women and hold them accountable for it. Women's role in the reduction of tensions also relates to 'supporting the reconstruction effort and participate to bring back peace, safety and stability' (Salah Al Din, KII, Tikrit,
Woman), or 'each one of us is dedicated to helping each other and to cooperate in order to minimise problems in the community and to bring about security and safety' (Anbar, Khalidya, FGD, Women).

\section{RECOMMENDATIONS FOR HUMANITARIAN AND RECOVERY PROGRAMMING}

This gender and conflict analysis has explored shifts in gender norms that have the potential to enhance gender-responsive and conflict-sensitive programming. The aim is to design, implement and monitor humanitarian and recovery programming that contributes to the reconfiguration of gender relations occurring in the current displacement context. This implies a two pronged approach: on the one hand, to address the needs underlying gender norms that potentially fuel conflict, exacerbate tensions, raise insecurity and increase vulnerability of the affected population; and on the other hand, enhance those gender norms that contribute to build trust, strengthen community cohesion and build resilience.

\section{Address gendered drivers that fuel community tensions.}

Diversify income generation opportunities to counter constructions of men as sole income providers.

Across the three study locations, access to livelihood opportunities has been identified as a key humanitarian and recovery need. Income-generating opportunities should be designed in such a manner to de-construct the belief and assumption that men are the sole providers of income. The lack of capacity of men to live up to gendered expectations as sole providers of income has led to increased frustration and has been linked to an increase in domestic and intimate-partner violence as a means to assert masculinity undermined by the perceived loss of power. This research has shown that women have engaged in paid work outside the home before and show a disposition to do so again in order to support their families. Income-generation activities need to be carefully designed in order to contribute to family cohesion and reduce tensions within the household. Provided the setting is appropriate, female income contributes to household stabilisation, while also 
enhancing women's capacity to decide how money is spent within the household if women earned some of the money.

Designing income-generating programmes in a genderresponsive and conflict-sensitive manner implies:

- Inclusive and participatory design of income generation projects: Addressing barriers to women's engagement in income generation opportunities Itoo much household responsibility, lack of consent from husband due to perceived inappropriateness in accordance to cultural norms).

- Plan income-generation options for women in a culturally acceptable way: Avoiding mixing with unrelated men; providing options within the home or in an enclosed area nearby.

- Pilot collaborative income-generation schemes between husbands and wives: Pilot and gather evidence around collaborative income generation schemes between husbands and wives that monitor patterns in household spending and decision-making.

- Target female headed households: Including widows, women whose husbands have been abducted, or women in households where the main income earner is not able to work.

- Women's collectives and collaborative work schemes, women's social enterprises: Pilot and gather evidence around women's collective and collaborative work schemes including women's social enterprises. These options will need to be appropriately funded and entail the provision of tools and resources, as well as training opportunities and specialised accompaniment.

- Women-only emergency livelihoods and income generation options: These could contribute to collective organising efforts, involving women from a different displacement status, and across ethnic and sectarian divides.

\section{Contribute to shifts in unpaid care work by reducing the prevailing stigmatisation.}

This research has shown that unpaid care work increases significantly for women and men in the context of displacement. Income-generating projects need to be designed in such a way as to enable women to live up to gendered expectations around care work, while at the same time exploring means to redistribute the workload of unpaid care work. Particular efforts should aim to reduce the prevailing stigmatisation of men who do engage in unpaid care work. The Rapid Care Analysis methodology in terms of research and stepping up the use of the methodology for awareness raising activities should be expanded. This implies the adoption of the simplest form of the RCA tools and processes consistent with local culture, assignment of dedicated staff for RCA and training to make them proficient in the use of the different tools, ${ }^{24}$ and embedding gender and care work consciousness among humanitarian staff. In terms of awarenessraising activities this would imply the more proactive involvement of men in unpaid care work, while reducing prevailing beliefs that make men feel emasculated for doing 'women's work'.

\section{Target vulnerable (unmarried) women, while increasing their peer-support structures.}

This research has identified the prevalence of stigmatisation according to lack of marital status: female heads of households, widows, survivors of abduction and divorcees. In the context of displacement, unmarried women continue to face considerable stigmatisation and do not have equal and equitable access to humanitarian and recovery assistance and face considerable constraints to participation in community decision-making. Selection criteria need to be further developed and paired with community consultation in order to navigate the complex dynamics of stigmatisation, while reducing the prevailing discrimination against related women who are not married (hence transgressing the socially accepted norms). Local women's organisations that are working in context sensitive ways to reach those vulnerable groups not reached by humanitarian and recovery assistance need to be supported.

\section{Enhancing gendered drivers that build trust Generate safe spaces for women and girls supporting their collective organising efforts.}

There is a reported need for women and girls-only safe spaces, based on perceptions that it is not appropriate for women to mix with unrelated men. A women's safe space can be a building that allows for indoor activities, such as arts and drawing for girls, as well as sports clubs for female youth (sports were possible, but only where these could also be indoors),

24. For example, how to probe further, sufficiently document information shared by the respondents, record the particularities of the immediate environment and the context of the participants to FGDs. 
but can also serve at times for income-generating activities. A women's safe space can also be used for regular activities, workshops or training sessions that generate the possibility to leave the home and establish relationships with other women in the community. Additional added value of safe spaces for women includes the possibility for targeted women's programming, which could be seen as a point for accessing information and services, and if desired, it could be used for organising collective efforts among women. Generating safe spaces for women and girls contributes to easing prevailing movement restrictions for them, while generating opportunities to start collective organising processes.

\section{Seize opportunities to enhance women's meaningful participation at community level.}

Given the shifts of power dynamics during ISIS occupation and the relative lack of community cohesion in contexts of displacement, international humanitarian and development actors need to devise localised approaches to engage with communities. Women have taken on roles as informal educators for their children and have been acknowledged for providing this. This recognition of women's roles in protecting their families can serve as entry point for humanitarian and recovery programming to enhance women's roles at the community level. Proactive efforts need to be made to capture women's voices, their contributions and provide spaces for timely, accurate and culturally acceptable dissemination of information. Programmes and interventions should invest in community dialogue, which promotes community ownership of aid interventions and thus increases their sustainability. Participatory communication with communities should seize the opportunity to draw attention to women's multiple roles in keeping families united and safe in order to increase communities' disposition to facilitate more active participation of women of different ages.

\section{Work with men and boys on the promotion of alternative gender roles as positive role models}

ISIS occupation significantly curtailed men's capacity to conform to cultural and societal expectations as providers and protectors, leading men to use violence against women to reassert that lost power and sense of masculinity. At the same time, prevailing gender norms also indicate opportunities for linking roles as protectors to positive role models and contributing to community reconstruction working across age divides.

References from study participants that indicate that women are increasingly stepping up in household decision-making on household expenses and awareness-raising methodologies (such as the RCAl can be used to stress women's contribution to household well-being, rather than framing women's participation as undermining the authority of the head of household. Since men continue to hold significant decision-making powers, their buy-in will be required to design effective women's rights, women's leadership and gender justice programming.

Adolescent men are reportedly tempted to join armed groups or militias because they had not done anything in a long time and opportunities to pursue independent income options to form their own family or to contribute to the income of their families of origin were curtailed. Female and male study participants stressed the importance of engaging with adolescent boys to keep them from joining armed groups. In another FGD, it was raised that adolescent men should engage in religious seminars to keep them from 'any lost ideology' (perceived as joining Daesh) (0xfam, 2017b). As such, working with men to seize their potential as positive role models, while enhancing spaces for women's participation at community level is recommended.

\section{Create and rehabilitate safe public spaces that enables joint work of community members.}

Under ISIS occupation movement restriction and gender segregation resulted in a scale-back of safe public spaces, confining more household members inside the home for longer periods, significantly increasing household tensions. Safe public spaces not only have symbolic significance in relation to ISIS retreating, but also provide an opportunity for families to be together. The Rapid Care Analysis in Diyala (Oxfam, 2017) also found that women proposed safe parks or places for children to play in the fields as an opportunity to ease the burden of unpaid care work. The reestablishment of safe public spaces and parks can also serve as an initial emergency cash-for-work opportunity, provided the necessary assessment is made, it could also serve as means (depending on the contextl for Remainees, Returnees and IDPs to work jointly. Parks, however, should be designated either with family times or times for women only. 


\section{Support local women's rights defenders and their organisations working with survivors of SGBV.}

Advocacy efforts of international humanitarian actors need to support local women's organisations working with female victims of sexual and genderbased violence, in order to overcome institutional constraints, as well as the criminalisation of their work by the authorities in response to cultural stigmatisation. In particular, women's shelters and safe houses that cater to the needs of women threatened by 'honour killings' and other forms of gender-based violence after they flee, require support in overcoming the perception that shelters encourage women to disobey their husbands, and daughters to disobey their parents, thus stigmatising shelters as places 'where a group of immoral women reside without a male guardian' which is viewed as likely to be a brothel, resulting in arbitrary surveillance and warrantless searches, hindering the operation of these shelters (IWHR, MADRE, OWFI, 2015).

It is necessary to support the reconstruction of networks of women's rights defenders and organisations in areas that were under ISIS control. Beyond the organisational and technical support, it is crucial to ensure the sustainability of their action through safety (including digitall trainings and support to their work on gender norms. In addition, appropriate flexible quality funding for their actions and initiatives should be provided. Support should amplify their voices by opening channels of networking with other national and regional women's rights organisations, as well as facilitate their access to and participation in relevant national, regional and international platforms and ensure their inclusion in relevant processes.

\section{Contribute to an inclusive, women-led and accountable Women, Peace and Security Agenda.}

This research highlights the roles that women can play as educators, in building lasting peace at the grassroots level and in preventing and countering violent extremism. This, however, needs to be done carefully in order to mitigate the risks often associated with these interventions, such as further emphasising the home-based role of women and further confining them to the domestic sphere; undermining the legitimacy and the duty of state-led processes to ensure the implementation of the Iraqi
National Action Plan on Women, Peace and Security; gearing the efforts of women's rights groups and donor contributions towards only community-based programming that is necessary, but not sufficient; and lastly making the prevention and countering of violent extremism the sole responsibility of women and holding them accountable for it as 'next generation educators'. As such, it is important that women's role in building peace and security is accompanied by their meaningful participation in the community and higher-level peace-building mechanisms, and that their contributions are acknowledged. Furthermore, concerted advocacy efforts need to be put in place to prosecute violence against women.

This report highlights the emergence of new forms of socio-economic marginalisation and vulnerability forming a rationale for social exclusion, especially for women and youth, based on their perceived affiliation to ISIS through their past marriages or relationships to ISIS sympathisers or fighters. It is therefore important to further explore the reasons and the various facets of this new form of vulnerability, to raise awareness and to mobilise the communities towards better understanding of the impact of the exclusionary processes and that Women's Rights Organisations and humanitarian actors advocate jointly for more inclusive peace negotiations and return processes.

\section{CONCLUSION}

This report has set out to go beyond the identification of the different impacts of ISIS occupation on women, girls, men and boys, in order to explore shifts in prevailing gender norms held by study participants in Anbar, Salah Al Din and Nineveh governorates of Iraq. The objective was to enhance the understanding of the social pressures women and men experience when aiming to live up to context-specific gendered expectations of masculinity and femininity, in order to derive concrete recommendations for genderresponsive and conflict-sensitive humanitarian and recovery programming. Furthermore, this study identifies concrete opportunities to adapt humanitarian and recovery programming to mitigate gendered drivers of conflict and tensions, while feeding in to gendered norms that contribute to stability and community cohesion. 
This research found that prevailing gender norms among study participants are based on a gendered difference and a gendered division of labour that tends to assign men responsibilities as protectors and providers, while attributing to women domestic roles and responsibilities that centre on the wellbeing of their families. Under ISIS occupation study participants experienced the imposition of a set of radicalised gender norms, which included the strict separation of women from unrelated men in public spaces, as well as rules about attire and daily practices that were enforced by brutal means. Consequently, study participants tended to comply with ISIS, but have sought to revert to their prevailing beliefs and attitudes, framed around gendered division of labour and gender roles, without continuing to abide by rules imposed under ISIS occupation. The current context of displacement constitutes a space where gender roles, responsibilities and practices are being re-negotiated, thereby generating entry points for gender-responsive, as well as gender-transformative humanitarian and recovery interventions.

The Saferworld method's focus on shifts in gender norms allowed the transcendence of the male perpetrator and female victim divide in order to identify underlying dynamics that fuel violence (including domestic violence), such as limited access to livelihoods, imposed movement restriction, and shifts of power relations within the household.

The exploration of gender norms that mitigate conflict and contribute to stability and community cohesion revealed that female study participants, in line with prevailing gender norms around domestic responsibilities, extended their scope of practices in the course of ISIS occupation to interpret wellbeing of the family in terms of protecting their children from joining ISIS, keeping their families safe and stressing the importance of education in a context where the formal school system was dismantled. The acknowledgement of women's diverse roles to keep their families safe and shifts in intra-household power dynamics constitutes a possible entry point to strengthen women's participation in contexts of displacement, as they strive to resume paid work, report an increase in joint decision-making within the households around household expenditures or express their interest in being more involved in community decision-making. A concerted effort by the humanitarian community to consistently consult different groups of women and ensure equal and equitable access to humanitarian and recovery assistance can contribute to women's meaningful participation in shaping interventions that enhance community cohesion.

Study participants indicate that men face considerable constraints in living up to their expected roles as the main household providers, as ISIS occupation exacerbated the pressures on men (who refused to join ISIS) by restricting movement and forcing the closure of businesses, while the ban of women in public spaces resulted in men assuming responsibilities of sole household providers. While access to livelihoods remains the greatest concern in displacement contexts, the humanitarian and recovery community can contribute to more flexible gender roles when promoting culturally acceptable opportunities (for women), and collaborative (between husband and wife) or collective (women's cooperatives) income generation options. Furthermore, this research shows that male study participants have also extended their understanding of their roles as protectors to serve as role models within the family in order to mitigate potential future tensions arising and contributing to community reconstruction efforts.

The humanitarian and recovery community can contribute to build back better and be more accountable to the affected population when adapting their programme interventions to ensure not only equal and equitable access to humanitarian and recovery assistance for men and women, but also to consider shifts in gender norms that comprise beliefs, attitudes and actual behaviours in their context analysis and programme design and implementation in ways that contribute to more egalitarian renegotiation of gender roles. Finally, gender-responsive and conflict-sensitive humanitarian and recovery programming can address the gender drivers that fuel conflict, exacerbate tensions and increase the vulnerability of affected populations, while enhancing those gender drivers that contribute to build trust, strengthen community cohesion and build resilience. 


\section{BIBLIOGRAPHY}

Abdulrazaq, T. and Stansfield, G. 2016. 'The Day After: What to Expect in post-Islamic State Mosul', in The RUSI Journal, 161:3, 14-20.

Amnesty International, 2014. Escape from hell: torture and sexual slavery in Islamic state captivity in Iraq, available at: https://www.amnesty.org.uk/ files/escape_from_hell___torture_and_sexual_ slavery_in_

Islamic_state_captivity_in_iraq_-_english_2.pdf, last accessed: 28 March 2017.

Ali, A. 2014. Security, Religion and Gender in AlAnbar Province, Iraq: A focus group-based conflict analysis

Care and Oxfam, 2015. Gender in Brief: Iraq. Available at: https://www.humanitarianresponse .info/en/ operations/iraq/assessment/gender-brief, last accessed on 30 March 2017.

Dagher, M.M. (2014). ISIL in Iraq: A disease or just the symptoms? A public opinion analysis - Second wave. IIACSS. Available at: http://csis.org/files/ publication/140930_Iraq_Survey.pdf, accessed on 31 March 2017

Eggert, J. P., 2015. Women Fighters in the 'Islamic State' and Al-Qaida in Iraq: A Comparative Analysis, in Die Friedens-Warte, vol. 90 (3-4): 363-380.

Hoyle, C., Bradford, A. and Frenett R., 2015. Becoming Mulan? Female Western Migrants to ISIS. Institute for Strategic Dialogue.

Human Rights Watch, 2016. Iraq: Women Suffer Under ISIS: For Sunnis, Lives Curtailed; for Yezidis, New Accounts of Brutal Rapes, 5 April 2016, available at: https://www.hrw.org/news/2016/04/05/iraqwomen-suffer-under-isis, last accessed, accessed on 28 March 2017.

IASC, 2014. Humanitarian Crisis in Iraq: Gender Alert. Available at: http://www.unwomen.org/-/media/ headquarters/attachments/sections/library/ publications/2014/iasc\%20final\%20gender\%20 alert $\% 20$ iraq $\% 2019 \% 20$ sept.pdf?vs $=1452$, accessed on 28 March 2017.

IASC, 2016. Guidelines for Integrating gender-based violence interventions in humanitarian action: reducing risk, promoting resilience and aiding recovery, available at: http://gbvguidelines.org/en/ home/, last accessed, 31 March 2017.

IWHR, MADRE and OWFI, 2015. Women's Human Rights violations in Iraq, in response to the fourth periodic report of the republic of Iraq, United Nations International Covenant of Economic, Social and Cultural Rights (ICESCR), 56th session, Geneva, Switzerland, 21 September-9 October 2015.

Jacoby, Tami Amanda (2015): Jihadi Brides at the Intersections of Contemporary Feminism, in New Political Science, vol. 37, issue 4, pp. 525-542. https://doi.org/10.1080/07393148.2015.1089028

Kidder, T. and Pionetti, C., 2013. Participatory Methodology: Rapid Care Analysis - Guidance for Managers and Facilitators, available at: http:// policy-practice.oxfam.org.uk/publications/ participatory-methodology-rapid-careanalysis-302415, last accessed on 28 March 2017.

Manell, T. and Roberson, S., 2015. Cohort Livelihoods and Risk Analysis: Designing safer livelihoods programs in Iraq, Oxfam, available at http://policypractice.oxfam.org.uk/publications/ clara-designing-safer-livelihoods-programs-iniraq-560876, last accessed 28 March 2017.

Oxfam Iraq, 2016d. Mosul-response - Gender Snapshot.

Oxfam Iraq, 2016ª. Iraq Gender Analysis: 'In the perfect world men would consult and respect us.'

Oxfam Iraq, 2016b. Rapid Care Analysis Report: Livelihoods Support and Asset Building in North Diyala (2016b)

Oxfam Iraq, 2016c. Report: including Women in livelihoods programming in Iraq: Influencing communities and other agencies in a fragile context.

Available at http://policy-practice.oxfam.org.uk/ publications/including-women-in-livelihoodsprogramming-in-iraq-influencing-communitiesand-620115, last accessed on 28 March 2018.

Oxfam Iraq, (forthcoming 2017). Rapid Care Analysis Report: Consolidated Report Northern Iraq Livelihood Assessment.

Oxfam, forthcoming 2017. Gendered Market Mapping in the Diyala and Kirkuk Governorates: A rapid Market Assessment in Northern Iraq. 
Rohwerder, B. (2014). Contemporary conflict analysis of Iraq (Rapid Literature Review). Birmingham, UK: GSDRC, University of Birmingham.

Saltman, E.M., Smith, M., 2015. 'Till Martyrdom Do Us Part'. Gender and the ISIS Phenomenon. ICSR / Institute for Strategic Dialogue.

Sider, R. and Sissons, C., 2016. 'Researching livelihoods recovery and support for vulnerable conflict-affected women in Iraq', in Gender $\delta$ Development, 24:3, 427-441.

United Nations Iraq, 2008. Gender-based violence in Iraq - the effects of violence - real and perceived - on the lives of women, girls, men and boys in Iraq, Joint Analysis Unit.

United Nations Assistance Mission in Iraq (UNAMI), 2013. Women in Iraq Factsheet, available at:

http://www.iau-iraq.org/documents/1864/WomanFactsheet.pdf, last accessed on 28 March 2017.

UNICEF, 2011. Iraq - MENA Gender Equality Profile: Status of Girls and Women in the Middle East and North Africa, available at: http://www.unicef.org/ gender/files/Iraq-Gender-Eqaulity-Profile-2011.pdf, last accessed on 28 March 2017.

UN Women, 2015. Global Study on the implementation of United Nations Security Council Resolution 1325, Preventing Conflict, Transforming Justice, Securing the Peace, available at: http:// wps.unwomen.org/, last accessed 31 March 2017.

\section{APPENDIX 1: WOMEN'S RIGHTS AND GENDER ANALYSIS IN IRAQ}

\section{Structural gender inequalities}

Structural gender inequalities are widespread in Iraq. However, these structural inequalities have changed over the past decades in accordance with shifting political and security contexts: 'During the Iran-Iraq war, Iraq's highly educated women took on traditionally male dominated roles in engineering and the military. By the 1990s, the Ba'ath Party, in alliance with conservative groups, changed approach to promote women's place in the home. since 2005 (passing of the new constitution), women's organisations have emerged but the continuing threat of insecurity has severely limited women's ability to exercise their rights and freedom of movement' (Care and Oxfam, 2015). Oxfam's Gender Snapshot for the Mosul Response (2016d) lists rights and freedoms under the national legal framework lincluding divorce rights, guardianship and custody rights, inheritance rights, freedom of movement and nationality rights) as well as Iraq's International commitments towards women's rights, including the Convention on the Elimination of All Forms of Discrimination against Women (CEDAW) and Convention on the Rights of the Child, stressing, however, the under-enforcement of this legal framework. Oxfam's Gender and Conflict Analysis (2017b) further stresses that pre-existing structural gender inequalities have been compounded by shifts in power alliances from modernising forces towards traditionalist conceptions, as religious and tribal codes $^{25}$ gain national traction and maintain women in subordinate positions in households, communities, and at regional and national level (IWHR, MADRE and OWFI, 2015).

Despite the fact that structural gendered inequalities may change over time, Oxfam's gender analysis $\left(2016^{a}\right.$ ) shows that study participants consistently view culture as set, defined and unchangeable. Consequently, when discussing power and gender relations, women tend to accept injustice and inequality as a natural and inevitable result of culture. This culture has clearly demarcated and reinforced specific roles and responsibilities for men (as providers) and women (in domestic care responsibilities) that result in pressure to conform. While some women expressed opinions that did not align with the prevailing cultural expectations, they felt unable to practise them in everyday life. For example, one interviewee said it was her dream to walk out of the house with the same freedom and lack of constraint as her husband, but was unable to do so because of 'the culture' (0xfam, 2016 $\left.{ }^{a}\right)$.

Oxfam's gender analysis (2016 a) argues that discrimination against women and their subordination rests on a traditional model of masculinity, which has been - in part - reinforced through war and violence. In those cases where men are not able to fulfil cultural expectations - notably around 'providing' - there is a significant increase in what women termed 'frustration' and 'anger'. This has resulted in men abusing those whom they perceive as weaker - their wives - in order to reassert their masculinity. Concurrently, Oxfam's gender and

25. This includes forced (often under-age) marriages as elements of tribal politics and economics (the practice involves two families or tribes who exchange women for marriage in place of a costly dowry or to pursue or renew tribal ties); marriage of women and girls as 'blood money', as a form of compensation to allow for settlements between tribes. Forced marriages also arise in the aftermath of rape, where a criminal trial may be suspended if the rapist agrees to marry the victim; and finally ordering bodily harm and assassination for having sexual relations outside marriage, and impunity for perpetrators of these human rights violations (IWHR, MADRE and OWFI, 2015). 
conflict analysis (2017b) also links the loss of livelihoods to an increase in domestic and intimatepartner violence. Furthermore, domestic violence receives widespread societal acceptance in Iraq, in a context where the Inter-Agency Information and Analysis Unit (IAU) reported that $56 \%$ of Iraqi men believe they have a right to beat their wife if she disobeys ${ }^{26}$ (IWHR, MADRE and OWFI, 2015). Although levels of divorce have increased leven with high stigma), living close to family (including an abusive husband) is perceived as a social and self-protection mechanism. Consequently, the effects of conflict, as well as the prevailing lack of enforcement of a legal framework around domestic violence, constitute barriers for women to leave violent relationships. Legal, health-related and psycho-social services for survivors of intimate partner and domestic violence need to be strengthened.

\section{Political participation at community level}

The 2005 constitution mandates that a quarter of the members of parliament be women. However, women's political representation and participation has not reached this threshold, compounded by the absence of women in local civil society and local government (IASC, 2014, Care and 0xfam, 2015). In addition to lapses in electoral cycles, male domination is particularly clear in relation to elections. Oxfam's gender analysis indicates that women do not feel that their needs and interests are being represented by their elected representatives. In addition to a lack of plausible female candidates, IDP women report that they do not choose for whom they vote, as their husband tells them who to vote for. The validation session of Oxfam's gender research indicates that even if women are elected, they may represent IDP women accordingly, or they may not be listened to if they do (0xfam, 2016 $)$.

At the same time, women's political participation at community level has been framed within the larger efforts to control, as well as criminalise women's political activism, a pattern that was exacerbated during Daesh occupation. Oxfam's gender snapshot (2016d) provides desktop research data on the targeted assassinations of women's rights defenders, women's activists and female politicians, as Daesh extended its occupation of Mosul. Consequently, studies with fieldwork components involving IDP, Returnee and Remainee population agree that women are largely excluded from decisionmaking at community level. For example, Oxfam's gender analysis $\left(2016^{a}\right)$ indicates that $92 \%$ of female respondents from the Kirkuk dataset report that they do not participate in local decision making.

Barriers to women's participation at the community level include 1) the lack of community space (lack of cohesive communities due to a constant influx of IDPS and Returnees); 2) perceptions of it being culturally unacceptable practice (for women); 3) not being invited or asked to participate; 4) women considering their own involvement in peace building and conflict management to be negligible; 5) women's level of participation relates to first addressing concerns around lacking income; and 6) being overburdened by responsibilities in the home l0xfam, 2016a; 0xfam, 2017b). Female-headed households and/or divorced women may face additional constraints on access or participating in community level decision-making spaces because of stigmatisation in relation to marital status (0xfam, 2016 $)$.

Nonetheless, qualitative data from different studies indicates a disposition of women to engage more in community-level decision-making when compared to times during occupation by Daesh. The Mosul dataset (Oxfam, 2017b) asks whether study participants consider that they have a role to play in solving major problems and challenges in their communities upon return to their communities of origin: $63 \%$ of female study respondents in Hassan Sham camp and $87 \%$ in Jeddah camp responded affirmatively. When prompted on which women should play a role in community decision-making, the women's FGD in Heet district in Anbar governorate suggested that educated women and those with a strong personality are best placed to participate. At the same time, female respondents also associate men earning a living with the potential for women to take up more active participation at the community level (Anbar, Khalidya, FGD, Women). Furthermore, female participants requested awareness-raising sessions and capacity building for some of the women who have a role in community (Anbar, Khalidya, FGD, Women). Concerted steps are required to overcome deeply ingrained beliefs and attitudes that men are the sole decision-makers at community level and consequently in peace building and engaging in conflict management. 


\section{Voice and decision-making within the household}

Voice and decision-making within the household also suggest a strong male dominance, which Oxfam's gender analysis $\left(2016^{a}\right)$ attributes to the significant disparity in power between husbands and wives. This is based on age disparity (women tend to be younger, as a result of early marriage) and the fact that the majority of men consider themselves to be the head of the household (84.7\% in Kalar and 94.1\% in Kirkuk). Oxfam's Gender Analysis (2016a) indicates that consultations within the house remain limited to issues within the ambit of traditional female roles, such as food and cooking. Women consistently explained that they are not consulted about other issues within the home, such as their husband marrying another wife, ${ }^{27}$ taking a job or travelling to another location. They are also not consulted on issues outside the home that affect their lives - whether on the issue of return or conflict mediation - 'if inside the house, the husbands consult us. If outside the house, only the men decide' lOxfam, 2016a). In contrast, primary qualitative data from the Mosul, Anbar and Salah Al Din dataset Igender and conflict analysis) indicate increasing joint decisionmaking between husbands and wives around whether children attend school, marriage of children and how money is spent. Female and male respondents reported more decision-making spaces for women, when compared to life under Daesh occupation. It is not clear, however whether this pattern constitutes a long-term change towards joint decision-making within the household or merely an improvement in comparison to life under Daesh (Oxfam, 2017b).

Shifts in patterns of decision-making within the household need to be considered an entry point for gender-responsive programming. Constraints on living up to idealised notions of masculinity allowed for male study participants to acknowledge the role of women in protecting their families through their care roles and, to the extent possible, reducing the impact of Daesh occupation on the household, which was not framed as a loss of power to men, but as contribution to the household (0xfam, 2017b).

\section{Sexual and gender-based violence}

The different studies conducted by Oxfam in Iraq indicate that gender-based violence and discrimination against women and girls has been a longstanding, pervasive problem in Iraq (UNICEF, 2011). Incidents of sexual and gender-based violence
(SGBV), include rape, honour killings (murder with mitigating circumstances), kidnapping and abduction, domestic violence, trafficking and prostitution, tribal practices and religiously motivated violence (UN Iraq, 2008, IWHR, MADRE and OWFI, 2015). Other acts of violence identified in Oxfam's gender analysis (2016 ${ }^{\text {a }}$ ) include beatings, forced prostitution, female genital mutilation and domestic violence, which represent significant threats to women and girls, causing severe physical and psychological harm to the victims. Sex and age disaggregated data on casualties by type of violence are limited and incidence of violence against women is largely underreported because of prevailing stigma, fear of retaliation and re-victimisation due to 'honour killing ${ }^{28}$ ' or lack of confidence in the police to investigate the complaint (UN Iraq, 2008). A particularly worrying trend emerged in the context of displacement in the Internal Disputed Boundaries: localised tensions between newly displaced people, Returnees and host communities were overlapping with multiple intertwined expressions of sexual and gender-based violence (SGBV) (domestic violence, rape, early/forced marriage, female genital mutilation/cutting), which were exacerbated by the depletion of assets, lack of livelihood opportunities, lack of privacy and general uncertainty (Oxfam, 2016c). The secondary data review within Oxfam's gender analysis (2016 ${ }^{\text {a }}$ ) also indicates that the legal system for handling GBV cases is flawed as police often discourage victims from filing complaints. In some cases, charges are brought against the victim, including adultery and rape and when not charged, and female victims of SGBV are often incarcerated for their 'own protection'. Interviewees consistently mentioned that they would not approach the police with a problem. During the validation session, some of the women shared that they have to deal with situations of abuse by themselves. They explained that before the displacement, they would turn to their family. Having been displaced, however, and having no means to travel (e.g. to parent's house), they were forced to stay at home with their abusers

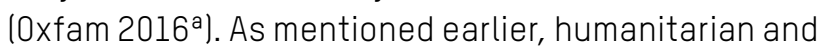
development actors must step up advocacy efforts to ensure the enforcement of the legal framework, while contributing to fund local women's rights organisations and those providing dignified support to survivors of SGBV through legal, health-related or psycho-social interventions.

27. Oxfam's gender analysis (2016 ${ }^{\text {a }}$ survey results in Kalar indicated that an astounding $94.4 \%$ of women said that men in their community engage in polygamy, while in Kirkuk, $72 \%$ of women stated that polygamy is commonly practised in their community. Women gave numerous explanations as to why their husbands were marrying more women - sometimes their wife was too old, too sick or did not give birth to enough sons.

28. The statistics are likely higher than those reported given the shame attached to reporting crimes of violence in a society where a family's honour is often tied to the chastity of its women. The victims of these crimes are frequently considered outcasts and can be killed for 'dishonouring' their family or their community. 'Honour killings' are usually perpetrated by male relatives and are perceived as a means of restoring a family's 'honour', when it has been tarnished by a woman's perceived 'immoral' behaviour. In a survey conducted by the UNFPA and the Iraqi government, $68 \%$ of young Iraqi men reported that they believe it is acceptable to kill a girl for damaging a family's honour. This is evident in the statistics. Approximately 1,270 honour-based crimes were reported in Iraq between 2004 and May 2008 - of these, 980 (or 77\%) occurred in KRI. (0xfam, 2016\%). It is notable that in the gender and conflict analysis (2017b) there was barely a mention of honour killing as affecting the household, although in the course of the validation session the enumerator reported that honour killings were mentioned off record. 


\section{APPENDIX 2: BRIEF DEMOGRAPHIC INFORMATION OF STUDY PARTICIPANTS}

This section briefly presents demographic information of study participants across the three locations of research, Nineveh (Mosul response), Anbar and Salah Al Din. For additional information and gender disaggregated data in Anbar and Salah Al Din that covers Community Protection, Livelihoods, Water, Sanitation, Community Engagement and Perceptions of Humanitarian Assistance, please see Oxfam's Multi Sectoral Needs Assessment Reports for Salah Al Din and Anbar (published May 2017).

Gender and age range of respondents

Data from the two sets of quantitative data analysis shows the following sex and age disaggregation. For the Mosul response, out of the total 234 households, ${ }^{29} 143$ (61\%) women and 91 (39\%) men completed the survey. The table below shows the age disaggregation.

Table A2.1: Sex and Age disaggregation of respondents, Mosul Response

\begin{tabular}{|c|l|l|l|l|l|}
\hline & \multicolumn{5}{|c|}{ Age Interval } \\
\cline { 2 - 6 } & $18-25$ & $26-40$ & $40-50$ & $50+$ & Total \\
\hline Female & 54 & 67 & 20 & 5 & 146 \\
\hline Male & 21 & 32 & 25 & 15 & 93 \\
\hline Total & 75 & 99 & 45 & 20 & $239 \mathrm{HH}$ \\
\hline
\end{tabular}

In Anbar, quantitative study participants included 107 (61\%) male and $68(39 \%)$ female respondents, while in Salah Al Din, 133 (62\%) men and 82 (38\%) women completed the household survey. The MSNA dataset does not capture the sex and age of respondents, but collects information on the average household size, as shown in the table below.

Table A2.2: Average household composition, Anbar and Salah Al Din governorates Anbar governorate Salah Al Din governorate

\begin{tabular}{|l|l|l|l|l|l|}
\hline \multirow{2}{*}{} & \multirow{2}{*}{ HH } & \multicolumn{5}{|c|}{ Age Interval } \\
\cline { 3 - 6 } & & $<5$ & $5-17$ & $18-59$ & $>60$ \\
\hline Female & 8 & 1 & 1 & 2 & 1 \\
\hline Male & & 1 & 1 & 2 & 1 \\
\hline
\end{tabular}

\begin{tabular}{|l|l|l|l|l|l|}
\hline \multirow{2}{*}{} & \multirow{2}{*}{ HH } & \multicolumn{5}{|c|}{ Age Interval } \\
\cline { 3 - 6 } & & $<5$ & $5-17$ & $18-59$ & $>60$ \\
\hline Female & 7 & 1 & 1 & 2 & 1 \\
\hline Male & & 1 & 1 & 1 & 1 \\
\hline
\end{tabular}

\section{Urban-rural background}

Given the state fragility in Iraq, territorial disputes (also linked to extractives and natural resource governance), contested areas and a high degree of internal displacement, this research aimed for a balance between urban and rural respondents. In Hassan Sham camp, 60\% report urban and 40\% report rural origin. This divide is more accentuated in Jeddah camp, where $77 \%$ of the respondents report to be of rural origin, in contrast to $23 \%$, who describe themselves of urban origin. The MSNA dataset shows that the respondents' population in Anbar governorate is largely urban $(85 \%)$, in comparison to $15 \%$ who report being of rural origin. In Salah Al Din governorate $50 \%$ of respondents were from rural areas and $50 \%$ from urban areas. While local and regional dynamics in a decentralised state are particularly important, identifying district-level patterns was beyond the scope of this research, but will need to be further established in the course of humanitarian programming. 


\section{Displacement Information}

In terms of displacement status, information was captured in the following three categories, Returnees, $66 \%$ in Anbar and 53\% in Salah Al Din; IDPs, 24\% in Anbar and 37\% in Salah Al Din; and Remainees (10\% in Anbar and Salah Al Din). In Salah Al Din, the IDP population is larger than in Anbar governorate, while the returnee percentage is lower, confirming overall displacement patterns in accordance to IOM's Displacement Tracking Matrix.

\section{Figure A2.1: Displacement status, Anbar and Salah Al Din governorates}

Anbar

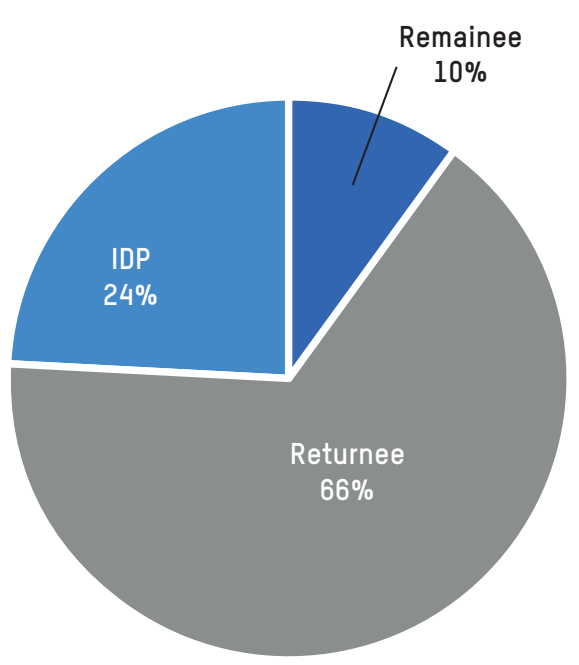

Salah Al Din

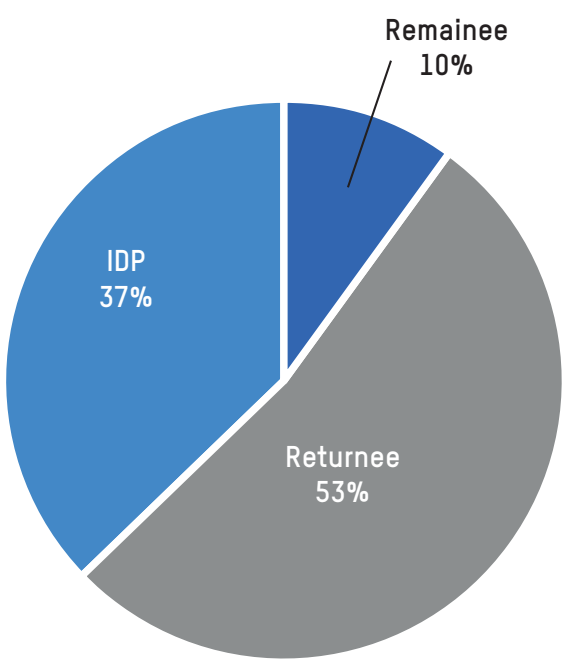

Women were proportionately represented (between $40 \%$ and $70 \%$ ) by displacement status. Data from Salah Al Din shows that IDPs and women are most likely to have been displaced two or more times compared to men who are most likely to have only been displaced once (along with rural respondents). Similarly, in Anbar governorate female respondents were more likely to report being displaced two (46\%) or three (19\%) times compared to men (29\% and $13 \%)$. Women are also more recent Returnees.

A greater proportion of women are living in less secure conditions to men, which increases their exposure to risks lincluding physical violence, dangerous coping strategies, begging, and physical risks due to limited water, sanitation and hygiene facilities). Female-headed households are particularly vulnerable. Quantitative data further shows that there is no difference between the percentage of women paying rent and men paying rent. However, women have less access to income-generating activities (IGA) than men, which puts them at an even greater risk of negative coping mechanisms to pay rent.

\section{Marital status and heads of household}

Of the Mosul Response study participants, $91 \%$ of men and $82 \%$ of women reported being married, while $12 \%$ of women and $9 \%$ of men report never having been married. The percentage of women who report being married is higher in Hassan Sham camp, $87 \%$ in comparison to $69 \%$ in Jeddah camp, resulting in a higher proportion of women in this location who have never been married, $9 \%$ in Hassan Sham camp and $18 \%$ in Jeddah camp. As shown in the chart below, only women report themselves as widowed $(5 \%)$ and divorced ( $1 \%)$. 
Figure A2.2: Marital status, Mosul data set combined

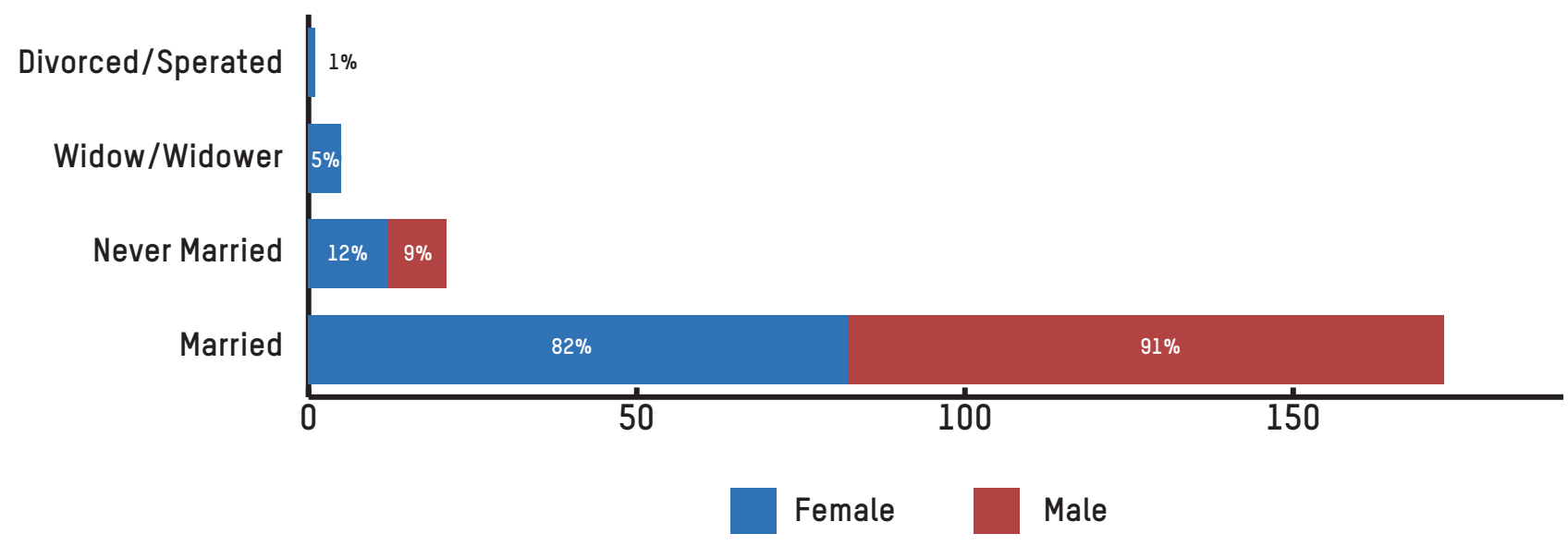

Figure A2.3 shows the percentage of respondents who reported being head of household in the Mosul dataset: $38 \%$ of women and $89 \%$ of men.

Figure A2.3: Percentage of respondents who reported being head of household, Mosul

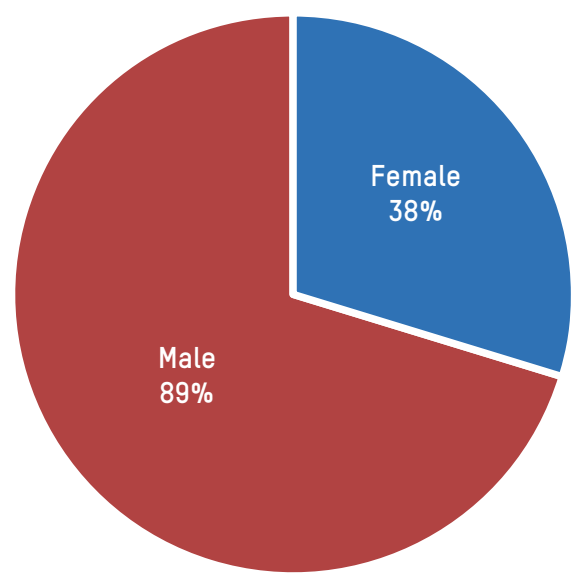

In Mosul, 38\% of female respondents reported being head of household. In Salah Al Din, of the 67 female respondents, $53(79 \%)$ were heads of household $(\mathrm{FHoH})$, representing $30 \%$ of the total surveys collected. Similarly, in Anbar, of the 66 female respondents, 60 (91\%) were the head of household, representing $28 \%$ of the total surveys conducted. The high percentage of females who reported being head of household may indicate an increase in overall FHoH following the conflict; however, this cannot be confirmed with the data collected.

\section{Education level}

In Salah Al Din governorate $90 \%$ of respondents reported that someone in their house could read lthere was no statistically significant difference between urban or rural, nor displacement status). In addition, 32\% of respondents had someone in their house attend university. There was no significant difference between urban and rural respondents, displacement status or gender in terms of highest level of education. 
In Anbar governorate, the most significant differences emerge across rural and urban divides, as $66 \%$ of rural and $96 \%$ of urban respondents report being able to read. There does not appear to be a difference according to gender of the respondents, nor by displacement status. Furthermore, 39\% of households in Anbar governorate report having someone who had completed university; however, this was only $20 \%$ of female respondents compared to $48 \%$ of male and only $9 \%$ of rural respondents compared to $44 \%$ of urban.

\section{Figure A2.4: Education and literacy level Anbar and Salah Al Din governorates}
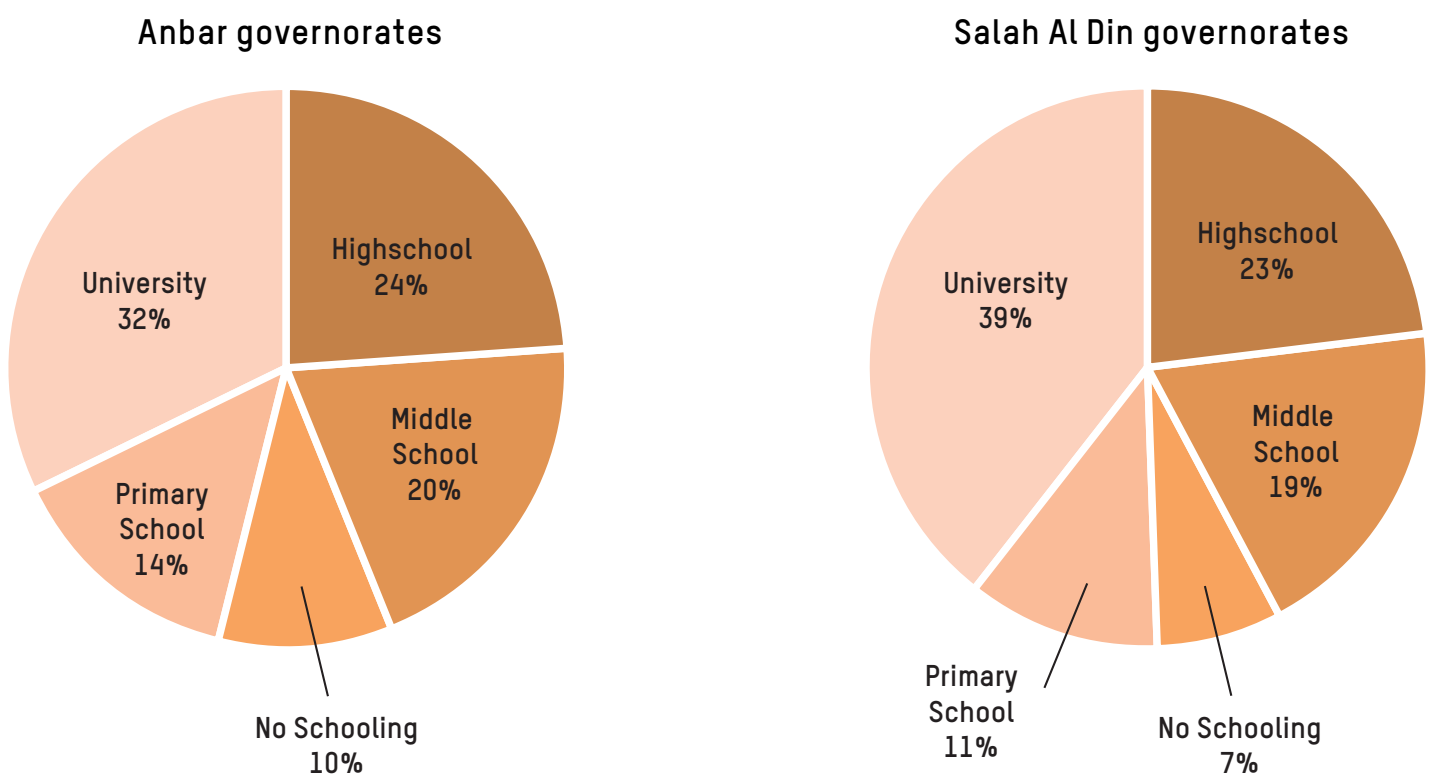

In the Mosul dataset, women were more likely to have no education (28\%) when compared to men (17\%), while men were more likely to have a university education ( $14 \%$ ) when compared to women (2\%).

Figure A2.5: Education level of respondents, Mosul dataset

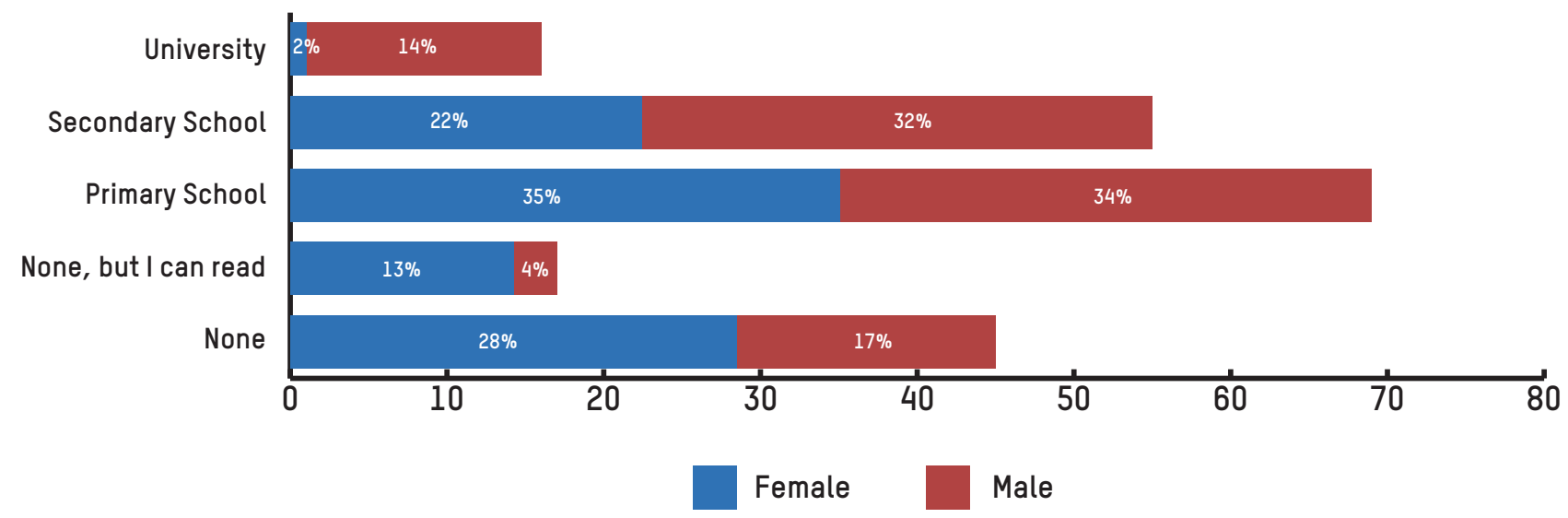

These figures are similar to UNICEF's report, ${ }^{30}$ which indicate an $87 \%$ (female) and $91 \%$ (male) participation in elementary school. This figure drops in middle school to $44.6 \%$ (female) and $51 \%$ (male), but highlights the prioritisation of education in households for both boy and girls at least until middle school. 


\section{Oxfam Research Reports}

Oxfam Research Reports are written to share research results, to contribute to public debate and to invite feedback on development and humanitarian policy and practice. They do not necessarily reflect Oxfam policy positions. The views expressed are those of the author and not necessarily those of Oxfam.

(C) Oxfam International May 2017

This publication is copyright but the text may be used free of charge for the purposes of advocacy, campaigning, education, and research, provided that the source is acknowledged in full. The copyright holder requests that all such use be registered with them for impact assessment purposes. For copying in any other circumstances, or for re-use in other publications, or for translation or adaptation, permission must be secured and a fee may be charged. Email policyandpractice@oxfam.org.uk.

The information in this publication is correct at the time of going to press.

Published by Oxfam GB for Oxfam International under

ISBN 978-0-85598-976-7 in May 2017.

DOI: $10.21201 / 2017.9767$

Oxfam GB, Oxfam House, John Smith Drive, Cowley, Oxford, OX4 2JY, UK.

\section{Oxfam}

Oxfam is an international confederation of 20 organizations networked together in more than 90 countries, as part of a global movement for change, to build a future free from the injustice of poverty. Please write to any of the agencies for further

information, or visit www.oxfam.org 